\title{
Fabrication of vertical orthorhombic/hexagonal tungsten oxide phase junction with high photocatalytic performance
}

Yesheng Li, ${ }^{a}$ Zilong Tang, ${ }^{*}$ a Junying Zhang ${ }^{*}, b$ and Zhongtai Zhang ${ }^{a}$

\section{Abstract}

The common one dimensional (1D) core-shell phase junction usually cannot fully utilize the separated charges because one phase is encapsulated inside, which leads to the incomplete release of the electrons or holes. Here, a unique vertical 1D/1D tungsten oxide phase junction constructed by orthorhombic $\mathrm{WO}_{3} \cdot 0.33 \mathrm{H}_{2} \mathrm{O}\left(\mathrm{o}-\mathrm{WO}_{3} \cdot 0.33 \mathrm{H}_{2} \mathrm{O}\right)$ nanorods and hexagonal $\mathrm{WO}_{3}\left(\mathrm{~h}-\mathrm{WO}_{3}\right)$ nanowires in the sunflower-like structure was fabricated via a facile one-step hydrothermal method. The nanorods and the nanowires vertically intersect at the endpoint to construct the vertical 1D/1D phase junction with another end exposed outside. This structure ensures that both two phases can contact the pollutants, so as to fully release the holes and electrons that accumulate on the o- $\mathrm{WO}_{3} \cdot 0.33 \mathrm{H}_{2} \mathrm{O}$ and h- $\mathrm{WO}_{3}$ phase, respectively. Furthermore, the two phases are both single crystals, substantially decreasing the impediments of defects to the transport of the photogenerated charges. This novel 
hierarchical structure with vertical $1 \mathrm{D}$ o- $-\mathrm{WO}_{3} \cdot 0.33 \mathrm{H}_{2} \mathrm{O} / \mathrm{h}-\mathrm{WO}_{3}$ phase junction can significantly improve the utilization efficiency of the separated photogenerated charges and thus effectively enhance the photocatalytic performance.

\section{Key Words}

sunflower-like $\mathrm{WO}_{3}$, vertical 1D/1D phase junction, charges utilization, solar light photocatalysis

\section{Introduction}

Semiconductor photocatalysts have been intensively investigated in the last decades as it is potential for the applications of environmental remediation and clean energy production.[1-8] To achieve this purpose, the key lies in developing proper photocatalysts that can harvest solar light and efficiently separate and transfer photogenerated charges. Various kinds of strategies have been proposed to improve separation and transfer efficiency of the photogenerated charges, among which fabrication of phase junctions is an effective approach.[9-12] The phase junctions in polymorph semiconductors, such as the anatase/rutile phase junction in $\mathrm{TiO}_{2}[2,13-20]$ and $\alpha / \beta$ phase junction in $\mathrm{Ga}_{2} \mathrm{O}_{3}[21-25]$ have been widely investigated. This kind of phase junction constructed by the different phases of the same semiconductor has attracted much attention due to its simplicity, controllability and great photocatalytic activity.[26][13]

Tungsten oxide with a band gap of $2.5-2.8 \mathrm{eV}$ is an attractive visible-light-sensitive photocatalyst in organic compounds decomposition, water splitting, and $\mathrm{CO}_{2}$ photoreduction.[26-28] It is also a kind of polymorph semiconductor which has many crystal phases including tetragonal, orthorhombic, monoclinic, hexagonal, triclinic and especially abundant hydrates (such as $\mathrm{WO}_{3} \cdot 2 \mathrm{H}_{2} \mathrm{O}$, $\mathrm{WO}_{3} \cdot \mathrm{H}_{2} \mathrm{O}, \mathrm{WO}_{3} \cdot 0.33 \mathrm{H}_{2} \mathrm{O}$ and so on). It greatly facilitates the construction of phase junction between 
different phases of tungsten oxides. Constructing phase junction should be useful for improving the charges separation efficiency of tungsten oxide. However, the photocatalytic activity dependence on the phase junction of tungsten oxides is still preliminarily investigated.[6,26,29,30]

Since one-dimensional (1D) nanostructure-based phase junction takes the advantages of 1D nanostructure in shortening the electron diffusion length and enhancing the light absorption,[31,32] fabricating 1D tungsten oxide phase junction should be a desirable strategy. The 1D phase junction was commonly constructed by one phase encapsulating the 1D phase to form the 1D core-shell structure.[2,17,18,20,32-34]The 1D core-shell phase junction could improve charges separation and transfer efficiency but it can't fully use the separated charges, because only one phase (the shell) could fully contact the reactants. For examples, the band structures of two phases favor the localization of the photogenerated electrons in the shell and the holes in the core. The holes couldn't be released completely [34] and thus were unable to play the full to react with the pollutants, which is not good for the utilization of the separated charges. There remains challenge of fabricating the phase junction that could fully utilize the separated charges.

Herein, a novel vertical 1D/1D tungsten oxide phase junction composed of orthogonal orthorhombic $\mathrm{WO}_{3} \cdot 0.33 \mathrm{H}_{2} \mathrm{O}\left(\mathrm{o}-\mathrm{WO}_{3} \cdot 0.33 \mathrm{H}_{2} \mathrm{O}\right)$ nanorods and hexagonal $\mathrm{WO}_{3}\left(\mathrm{~h}-\mathrm{WO}_{3}\right)$ nanowires in the sunflower-like hierarchical structure was synthesized by a simple one-step hydrothermal method. In this structure, the $\mathrm{o}-\mathrm{WO}_{3} \cdot 0.33 \mathrm{H}_{2} \mathrm{O}$ nanorod and $\mathrm{h}-\mathrm{WO}_{3}$ nanowire substantially vertically intersect at the endpoint to construct the vertical 1D/1D phase junction, while another ends of the nanowire and nanorod are exposed. This structure ensures the spatial separation of the photo-generated electrons and holes, and both the two phases can contact the pollutants and release the separated charges. As a result, the phase junction exhibits superior photocatalytic activities in comparison with 
the component phases. The photocurrents and electrochemical impedance spectra confirm the high charge separation efficiency of the phase junction.

\section{Experimental}

All chemicals were purchased from the Sinopharm Chemical Reagent Co., Ltd and were of analytical reagent grade and used without further purification. All the aqueous solutions were prepared using deionized water.

\subsubsection{Synthesis of the sunflower-like tungsten oxide.}

A facile one-step hydrothermal method was used to synthesize the sunflower-like tungsten oxide. Typically, $1.25 \mathrm{~g} \mathrm{H}_{2} \mathrm{WO}_{4}$ was added into $25 \mathrm{~mL} \mathrm{H}_{2} \mathrm{O}_{2}$, stirred at $90{ }^{\circ} \mathrm{C}$ for $1.5 \mathrm{~h}$ before converting into a transparent sol. The resulting clear sol was diluted to $60 \mathrm{ml}$ using deionized water, and then 42 $\mathrm{mL}$ of the sol were taken out and diluted to $224 \mathrm{~mL}$ using deionized water. After stirring for another $20 \mathrm{~min}, 30 \mathrm{~mL}$ of the precursor solution was transferred into a $50 \mathrm{~mL}$ Teflon-lined autoclave followed by adding a certain amount of $\mathrm{NaCl}$. Finally, the autoclave was sealed and maintained at $180{ }^{\circ} \mathrm{C}$ for $4 \mathrm{~h}$. The as-synthesized precipitate was washed with deionized water for three times and ethanol for two times, and then dried in vacuum at $80{ }^{\circ} \mathrm{C}$ for $5 \mathrm{~h}$. The samples prepared by adding different amount of $\mathrm{NaCl}$ were labelled as WNC-1 $(0 \mathrm{~g} \mathrm{NaCl})$, WNC-2 $(0.1 \mathrm{~g} \mathrm{NaCl}), \mathrm{WNC}-3(0.2 \mathrm{~g}$ $\mathrm{NaCl})$ and $\mathrm{WNC}-4(0.4 \mathrm{~g} \mathrm{NaCl})$.

\subsubsection{Photo-deposition of Pt or $\mathrm{MnO}_{\mathrm{x}}$ on the sunflower-like tungsten oxide.}

Typically, $1.6 \mathrm{~mL} 2 \mathrm{mg} \mathrm{L} \mathrm{H}_{2}^{-1} \mathrm{PtCl}_{6} \cdot 6 \mathrm{H}_{2} \mathrm{O}$ solution and $2 \mathrm{~mL} \mathrm{CH} \mathrm{CH}_{3} \mathrm{OH}$ were added in the $38 \mathrm{~mL}$ WNC-2 suspension which contains $20 \mathrm{mg}$ WNC-2 powder. Then, the suspension was irradiated under $300 \mathrm{~W}$ Xenon lamp for $1 \mathrm{~h}$. The products were isolated by centrifugation and washed with 
deionized water for several times. Similarly, the photo-oxidization of $\mathrm{MnO}_{\mathrm{x}}$ was performed with $\mathrm{MnSO}_{4} \cdot \mathrm{H}_{2} \mathrm{O}$ as precursor and $\mathrm{NaIO}_{3}$ as electron acceptor.

\subsection{Measurements of photocatalytic and photoelectrochemical properties.}

The photocatalytic properties of the samples were evaluated by measuring the concentration of rhodamine $\mathrm{B}(\mathrm{RhB})$, methyl orange $(\mathrm{MO})$ and colorless phenol in aqueous solution after irradiation with simulated solar light produced by a $300 \mathrm{~W}$ Xenon lamp. Typically, $20 \mathrm{mg}$ sample was dispersed in $40 \mathrm{~mL}$ dye aqueous solution $\left(15 \mathrm{mg} \mathrm{L}^{-1}\right)$. Prior to irradiation, the suspension was stirred over night to ensure the equilibrium of dye adsorption on the surfaces of the sample. The dye concentration was measured by UV-Vis spectroscopy. The photodegadation of phenol $(10 \mathrm{mg} / \mathrm{L})$ was conducted in a similar procedure to the dye. The concentration of phenol was determined by the chromatographic experiments performed using an HPLC-UV/Vis system with an ultraviolet absorbance detector (K2501) operated at $270 \mathrm{~nm}$ and a Venusil XBP-C ${ }_{18}$ (Agela Technologies Inc.) column.

The photocurrents and electrochemical impedance spectra (EIS) were measured on an electrochemical workstation (CHI-660E, China) and carried out in a three-electrode system with a working electrode, a platinum wire as counter electrode and a standard calomel electrode (SCE) as reference electrode. $0.1 \mathrm{M} \mathrm{Na}_{2} \mathrm{SO}_{4}$ was used as the electrolyte solution. The photocurrent responses of the photocatalysts were measured at $0.0 \mathrm{~V}$ (vs. SCE). The EIS data were carried out at frequencies from $100 \mathrm{mHz}$ to $100 \mathrm{kHz}$ with a magnitude of $5 \mathrm{mV}$ at open-circuit potential. The working electrodes were prepared by a dip-coating method: $10 \mathrm{mg}$ photocatalyst was suspended in $1 \mathrm{~mL}$ 1-methyl-2-pyrrolidinone (NMP) to make a slurry, and the slurry was then dip-coated onto a $2 \times 3.5$ cm fluorine-tin oxide (FTO) glass. The as-prepared electrodes were dried at $80{ }^{\circ} \mathrm{C}$ for $10 \mathrm{~h}$ in air before measurement. 


\subsection{Characterization of materials.}

The X-ray diffraction patterns were obtained on a Rigaku D/max-V2500 ( $\mathrm{Cu}$ K $\alpha$ radiation). High-resolution Raman spectroscopy (HR800, Horiba Jobin Yvon, France) were used to collect the Raman spectra. The morphology and microstructure were studied by scanning electron microscopy (SEM, Zeiss, Germany) and transmission electron microscopy (TEM, JEOL-2100F, Japan). The X-ray photoelectron spectroscopy (XPS) measurements were determined on an Escalab 250Xi instrument (Thermo Fisher Scientific, USA). UV-Vis spectrophotometer (U-3010, Hitachi, Japan) was used to record UV/Vis absorption spectra. The surface areas of the samples were measured by the Brunauer-Emmett-Teller (BET) method using nitrogen adsorption-desorption isotherms at $77 \mathrm{~K}$ with a Contador QuadraSorb SI-MP instrument. The Mott-Schottky plots were measured on an electrochemical workstation (CHI-660E, China) and carried out in a three-electrode system (counter electrode: Pt; reference electrode: standard calomel electrode (SCE); electrolyte: $0.1 \mathrm{M} \mathrm{Na}_{2} \mathrm{SO}_{4}$, frequency: 1000Hz). The photoluminescence (PL) measurements are taken at room temperature using a xenon lamp (Xe900) with an excitation wavelength of $350 \mathrm{~nm}$. Electron spin resonance spectroscopy (ESR) measurements were performed at room temperature with a JEOL FA200 ESR spectrometer under simulated solar light.

\section{Results and discussion}

\subsection{Structure and morphology.}

The XRD patterns of tungsten oxides prepared using different amount of $\mathrm{NaCl}$ were presented in Fig. 1. The (111) diffraction peak at about $18.1^{\circ}$ is the characteristic peak of orthorhombic $\mathrm{WO}_{3} \cdot 0.33 \mathrm{H}_{2} \mathrm{O}$ $\left(\mathrm{o}-\mathrm{WO}_{3} \cdot 0.33 \mathrm{H}_{2} \mathrm{O}\right)$, because there is no peak in this position for hexagonal $\mathrm{WO}_{3}\left(\mathrm{~h}-\mathrm{WO}_{3}\right)$. The peaks 
of WNC-1 can be well indexed to o- $\mathrm{WO}_{3} \cdot 0.33 \mathrm{H}_{2} \mathrm{O}$ (JCPDS no. 72-0199) when no $\mathrm{NaCl}$ was added (Fig. 1a). While as the amount of $\mathrm{NaCl}$ was increased to $0.4 \mathrm{~g}$, WNC-4 yields a pure $\mathrm{h}-\mathrm{WO}_{3}$ phase, with the XRD pattern corresponding to JCPDS no. 75-2187 (Fig. 1a). It seems that WNC-2 can be attributed to the $\mathrm{o}-\mathrm{WO}_{3} \cdot 0.33 \mathrm{H}_{2} \mathrm{O}$ and $\mathrm{WNC}-3$ can be assigned to the $\mathrm{h}-\mathrm{WO}_{3}$, as shown in Fig. 1a. However, the peak intensities of WNC-2 at about 14.0 and $18.1^{\circ}$ and their intensity ratio are obviously different from those of WNC-1. There is a small peak at $18.1^{\circ}$ in WNC-3 which would not appear in the $\mathrm{h}-\mathrm{WO}_{3}$. In order to gain insight into the detailed phase information, a numerical deconvolution technique was used. The major phase of $\mathrm{WNC}-2$ is $\mathrm{o}-\mathrm{WO}_{3} \cdot 0.33 \mathrm{H}_{2} \mathrm{O}$, since it has the obvious peak of (111). But after deconvolution, the peak at about $14.0^{\circ}$ can be separated into two peaks belonging to $\mathrm{h}-\mathrm{WO}_{3}(100)$ and $\mathrm{o}-\mathrm{WO}_{3} \cdot 0.33 \mathrm{H}_{2} \mathrm{O}(020)$, respectively, as shown in Fig. $1 \mathrm{~b}$, suggesting that there exists $\mathrm{h}-\mathrm{WO}_{3}$ phase in WNC-2. Similarly, from the enlarged XRD pattern (at range of $10-20^{\circ}$ ) in Fig. 1c, the o- $\mathrm{WO}_{3} \cdot 0.33 \mathrm{H}_{2} \mathrm{O}$ (111) peak can be clearly observed and only one peak can be separated in the range of $12-16^{\circ}$ (the inset), indicating that WNC-3 not only has h- $\mathrm{WO}_{3}$ but also has a small part of $\mathrm{o}-\mathrm{WO}_{3} \cdot 0.33 \mathrm{H}_{2} \mathrm{O}$. In summary, WNC-1 and WNC-4 belong to pure $\mathrm{o}-\mathrm{WO}_{3} \cdot 0.33 \mathrm{H}_{2} \mathrm{O}$ and $\mathrm{h}-\mathrm{WO}_{3}$, respectively, WNC-2 contains the major phase of $\mathrm{o}-\mathrm{WO}_{3} \cdot 0.33 \mathrm{H}_{2} \mathrm{O}$ and a part of $\mathrm{h}-\mathrm{WO}_{3}$, and $\mathrm{h}-\mathrm{WO}_{3}$ is the main phase in $\mathrm{WNC}-3$.

The further phase information of the samples was investigated using Raman spectroscopy. The peaks centered at about $255,334,472,688,800$, and $950 \mathrm{~cm}^{-1}$ in $\mathrm{WNC}-1$, are assigned to the $\mathrm{o}-\mathrm{WO}_{3} \cdot 0.33 \mathrm{H}_{2} \mathrm{O}$, as shown in Fig. 2. The peaks at 255 and $334 \mathrm{~cm}^{-1}$ are assigned to the W-O-W bending vibration of the bridging oxygen $[\delta(\mathrm{W}-\mathrm{O}-\mathrm{W})]$. The peaks at around 688 and $800 \mathrm{~cm}^{-1}$ are attributed to the stretching vibration of O-W-O [v (O-W-O)].[35] The peaks at around 472 and 950 
$\mathrm{cm}^{-1}$ are assigned to the stretching mode of $\mathrm{W}-\mathrm{OH}_{2}$ and the terminal $\mathrm{W}=\mathrm{O}$ bond, respectively, which are typical peaks for tungsten oxide hydrates.[36] The peaks of $\mathrm{h}-\mathrm{WO}_{3}$ centered at about 241,325 , 674 , and $813 \mathrm{~cm}^{-1}$ are found in WNC-4. The peaks at 241 and $325 \mathrm{~cm}^{-1}$ are assigned to $\delta$ (W-O-W) and the peaks at around 674 and $813 \mathrm{~cm}^{-1}$ are attributed to $v(\mathrm{O}-\mathrm{W}-\mathrm{O})$. As for WNC-2, the peak at $800 \mathrm{~cm}^{-1}$ red shifts to $808 \mathrm{~cm}^{-1}$ and all the other peaks are blue shifted compared with WNC-1 (Fig. 2). The Raman peaks in WNC-3 are similar to those in WNC-4, except that the peak shifts from 674 to $679 \mathrm{~cm}^{-1}$ and a peak at $950 \mathrm{~cm}^{-1}$ is observed, as shown in Fig. 2. The shifts of Raman peaks in WNC-2 and WNC-3 compared with WNC-1 and WNC-4, in turn confirm the analysis of XRD patterns, i.e. both WNC-2 and WNC-3 have two phases.

The morphology variations of the as-prepared samples are shown in Fig. 3 and Fig. S1. It shows that the sample appears with a ball-flower-like structure assembled with numerous rectangular nanoplates (about $100 \mathrm{~nm}$ thick) when no $\mathrm{NaCl}$ was used (Fig. S1a and b), while as the $\mathrm{NaCl}$ was added in the hydrothermal solution, the samples WNC-2, WNC-3 and WNC-4 all show the sunflower-like shape (Fig. 3 and Fig. S1c). The morphologies in the center region of the sunflower-like structures are similar among WNC-2, WNC-3 and WNC-4, as shown in Fig. 3i, all exhibiting nanowire bundle arrays. The area of the nanowire bundle arrays enlarges as the amount of $\mathrm{NaCl}$ increases, i.e. WNC-4>WNC-3>WNC-2. However, the outer regions of the sunflower-like structures are different among these three samples. WNC-2 is assembled with nanorods in the outer region (Fig. 3a-c), while the thinner nanorods are linked each other into flake-like shape in the edge of WNC-3 (Fig. 3d-g) and the edge of the WNC-4 is smooth without nanorods (Fig. S1d). Moreover, from the enlarged pictures of the corresponding rectangular region (Fig. $3 \mathrm{c}$ and e), it is revealed that 
the inner nanowires and outer nanorods are substantially vertically intersect in WNC-2 and WNC-3. Meanwhile, a fractured sunflower-like structure was further investigated to confirm the vertical relation of the nanorods and nanowires, as shown in Fig. 3f-h. Above all, the WNC-1 has no nanowire bundles but thick nanoplates and the WNC-4 is completely assembled with nanowire bundles; the WNC-2 and WNC-3 contain orthogonal nanorods and nanowire bundles. The XRD patterns show that the WNC-1 is pure $0-\mathrm{WO}_{3} \cdot 0.33 \mathrm{H}_{2} \mathrm{O}, \mathrm{WNC}-4$ is pure $\mathrm{h}-\mathrm{WO}_{3}$ and $\mathrm{WNC}-2$ and WNC-3 are composed of two phases, suggesting that the nanorods and nanowires may correspond to different crystal phases.

To further analyze the morphology and the crystal phase of the samples, TEM images of the samples were recorded. WNC-2 and WNC-3 containing two kinds of building block-the nanorods and the nanowires-can be confirmed by the TEM images, as shown in Fig. S2. In order to study the structure of the nanorod and nanowire, the HRTEM images were taken and shown in Fig. 4. The spacing of the lattice fringes of the nanoplate in WNC-1 are found to be 0.385 and $0.372 \mathrm{~nm}$, which can be well indexed as (002) and (200) planes of the o- $\mathrm{WO}_{3} \cdot 0.33 \mathrm{H}_{2} \mathrm{O}$, as shown in Fig. $4 \mathrm{a}$. WNC-2 contains two kinds of building block: the spacing of the lattice fringes of the thick nanorod are 0.319 and $0.315 \mathrm{~nm}$ corresponding to (220) and (040) planes of the o- $\mathrm{WO}_{3} \cdot 0.33 \mathrm{H}_{2} \mathrm{O}$ (Fig. 4b), and the nanowire with a width at about $20 \mathrm{~nm}$ has the spacing of the lattice fringes of 0.391 and $0.365 \mathrm{~nm}$ belonging to $\mathrm{h}-\mathrm{WO}_{3}$ (Fig. 4c). Similarly, the nanorod in WNC-3 with the spacing of the lattice fringes about $0.385,0.368$ and $0.266 \mathrm{~nm}$ are assigned to $\mathrm{o}-\mathrm{WO}_{3} \cdot 0.33 \mathrm{H}_{2} \mathrm{O}$ and the nanowire belongs to $\mathrm{h}-\mathrm{WO}_{3}$ (Fig. $4 \mathrm{~d}$ and e). Moreover, the nanowire in WNC-4 belonging to $\mathrm{h}-\mathrm{WO}_{3}$ shows similar value of the spacing of the lattice fringes to those of the nanowire in WNC-2 and WNC-3. The 
well-fined lattice fringes demonstrate that both the nanorod and nanowire are single crystal. The results of XRD patterns, Raman spectra and HRTEM images clearly demonstrate that the sunflower-like WNC-2 and WNC-3 are assembled with both o- $\mathrm{WO}_{3} \cdot 0.33 \mathrm{H}_{2} \mathrm{O}$ and $\mathrm{h}-\mathrm{WO}_{3}$, and the thick nanorods in the outer region of the sunflower-like structure belong to o- $\mathrm{WO}_{3} \cdot 0.33 \mathrm{H}_{2} \mathrm{O}$ and the thin nanowires in the centre region are $\mathrm{h}-\mathrm{WO}_{3}$. Therefore, it can infer that the phase junction constructed by nanorod-like $\mathrm{o}-\mathrm{WO}_{3} \cdot 0.33 \mathrm{H}_{2} \mathrm{O}$ and nanowire-like $\mathrm{h}-\mathrm{WO}_{3}$ should exist in sunflower-like WNC-2 and WNC-3.

As mentioned above, the addition of $\mathrm{NaCl}$ would result in the production of sunflower-like tungsten oxide. And the amount of $\mathrm{NaCl}$ is very important for the formation of sunflower-like $\mathrm{o}-\mathrm{WO}_{3} \cdot 0.33 \mathrm{H}_{2} \mathrm{O} / \mathrm{h}-\mathrm{WO}_{3}$ phase junction. The relationship between the amount of $\mathrm{NaCl}$ and the morphology and crystal phase of the tungsten oxide is illustrated in Fig. 5. Many references reported that $\mathrm{NaCl}$ could be the capping agent that leads to the formation of $1 \mathrm{D}$ tungsten oxide nanorods or nanowires.[37,38] $\mathrm{NaCl}$ could selectively adsorb onto the crystal planes parallel to the c-axes of tungsten oxide crystal nuclei. Then the growth of those crystal planes would be impeded, while the crystal plane perpendicular to c-axes would grow faster, thus leading to the preferential growth along $c$-axis.[37] In some cases, $1 \mathrm{D}$ nanorod could also be synthesized by using $\mathrm{Na}_{2} \mathrm{WO}_{4}$ and $\mathrm{HCl}$ as raw materials, $[39,40] \mathrm{Na}^{+}$from $\mathrm{Na}_{2} \mathrm{WO}_{4}$ and $\mathrm{Cl}^{-}$from $\mathrm{HCl}$ may play similar role to $\mathrm{NaCl}$. Besides, the $\mathrm{Na}^{+}$could insert into the hexagonal channel to stabilize the hexagonal structure.[41,42] Therefore, the addition of $\mathrm{NaCl}$ could facilitate the formation of $\mathrm{h}-\mathrm{WO}_{3}$ nuclei and their steady growth during the reaction, thus resulting in the production of $\mathrm{h}-\mathrm{WO}_{3}$. The $\mathrm{o}-\mathrm{WO}_{3} \cdot 0.33 \mathrm{H}_{2} \mathrm{O}$ and $\mathrm{h}-\mathrm{WO}_{3}$ nuclei could co-exist in the hydrothermal solution by adding a certain amount of $\mathrm{NaCl}(0.1$ or $0.2 \mathrm{~g})$. In 
addition, the hydrogen bond in the solution can induce the self-assembly of the primary self-aggregates, while van der Waals forces are favorable for enhancing the stability of the formed superstructures (such as the sunflower-like hierarchical structure).[39] Thereby, the $\mathrm{h}-\mathrm{WO}_{3}$ nuclei with $\mathrm{NaCl}$ around them prefer to gather together, while the o- $\mathrm{WO}_{3} \cdot 0.33 \mathrm{H}_{2} \mathrm{O}$ nuclei tend to grow attached to the $\mathrm{h}-\mathrm{WO}_{3}$. Then sunflower-like tungsten oxide hierarchical structure with 1D $\mathrm{o}-\mathrm{WO}_{3} \cdot 0.33 \mathrm{H}_{2} \mathrm{O} / \mathrm{h}-\mathrm{WO}_{3}$ phase junction would form.

\subsection{The energy band position of the $\mathrm{o}-\mathrm{WO}_{3} \cdot 0.33 \mathrm{H}_{2} \mathrm{O} / \mathrm{h}-\mathrm{WO}_{3}$ phase junction}

To experimentally confirm the existence of the o- $\mathrm{WO}_{3} \cdot 0.33 \mathrm{H}_{2} \mathrm{O} / \mathrm{h}-\mathrm{WO}_{3}$ phase junction, the $\mathrm{Pt}$ and $\mathrm{MnO}_{\mathrm{x}}$ particles were photo-deposited on WNC-2. If the phase junction was successfully fabricated in the sunflower-like tungsten oxide hierarchical structure, the photo-generated electrons would transfer from one phase to another phase and the holes transfer in the opposite direction. As a result, the Pt could selectively deposit on one phase containing more electrons and the $\mathrm{Mn}^{2+}$ would be photo-oxidized on another phase with more holes, when $\mathrm{H}_{2} \mathrm{PtCl}_{6} \cdot 6 \mathrm{H}_{2} \mathrm{O}$ or $\mathrm{MnSO}_{4} \cdot \mathrm{H}_{2} \mathrm{O}$ was added in the WNC-2 suspension under irradiation. Fig. S3 is the XRD patterns and XPS spectra of WNC-2 after photo-depositing $\mathrm{Pt}$ or $\mathrm{MnO}_{\mathrm{x}}$. No obvious diffraction peaks of $\mathrm{Pt}$ or $\mathrm{MnO}_{\mathrm{x}}$ are found from the XRD patterns in Fig. S3a, perhaps due to the low amount or the poor crystallinity of $\mathrm{Pt}$ or $\mathrm{MnO}_{\mathrm{x}}$. However, the peak of Pt 4f (Fig. S3b) or Mn 2p (Fig. S3c) can be observed from the XPS spectra, suggesting that Pt or $\mathrm{MnO}_{\mathrm{x}}$ was successfully deposited on the WNC-2. Meanwhile, the SEM images were also taken after photo-depositing Pt or $\mathrm{MnO}_{\mathrm{x}}$ as presented in Fig. S4. Fig.S4a and d show that photo-depositing Pt or $\mathrm{MnO}_{\mathrm{x}}$ did not change the morphology of WNC-2. The nanowires in the center show similar morphology to those before depositing Pt (Fig. S4b), while some nanoparticles can be 
observed on the nanorods after depositing Pt (Fig. S4c). As for the sample after depositing $\mathrm{MnO}_{\mathrm{x}}$, it is a little difficult from Fig. S4e to distinguish whether there is $\mathrm{MnO}_{\mathrm{x}}$ on the nanowires, possibly due to the small size of $\mathrm{MnO}_{\mathrm{x}}$ nanoparticles. But Fig. S4f shows that the nanorods are smooth, suggesting that they may be free of $\mathrm{MnO}_{\mathrm{x}}$. For better confirming whether the $\mathrm{Pt}$ or $\mathrm{MnO}_{\mathrm{x}}$ has been loaded on the $\mathrm{h}-\mathrm{WO}_{3}$ nanowires or $\mathrm{o}-\mathrm{WO}_{3} \cdot 0.33 \mathrm{H}_{2} \mathrm{O}$ nanorods, the typical TEM images, energy dispersive spectrometer (EDS) analysis, bright-field scanning transmission electron microscopy (BF-STEM), and electron energy loss spectroscopy (EELS) chemical mapping of the nanorod and nanowire in WNC-2 after photo-depositing Pt or $\mathrm{MnO}_{\mathrm{x}}$ were presented in Fig. 6 and Fig. S5. The typical TEM images (Fig. S5a and b) show that no Pt particles were found on the surface of the h- $\mathrm{WO}_{3}$ nanowire. However, many Pt particles were found on the surface of the o- $\mathrm{WO}_{3} \cdot 0.33 \mathrm{H}_{2} \mathrm{O}$ nanorod, as shown in Fig. 6a and b. It can be further confirmed by EDS analysis and EELS chemical mapping results, as shown in Fig. 6c-g. On the other hand, sponge-like manganese oxide deposits were formed on the $\mathrm{h}-\mathrm{WO}_{3}$ nanowire (Fig. $6 \mathrm{~h}$ and $\mathrm{i}$ and Fig. S5c and d). HRTEM images in Fig. 6i and Fig. S5d show that the planar spaces of 0.272 and $0.166 \mathrm{~nm}$ well match the (222) and (440) planes of cubic $\mathrm{Mn}_{2} \mathrm{O}_{3}$, and the planar space of $0.166 \mathrm{~nm}$ is in accordance with the (102) plane of hexagonal $\mathrm{MnO}_{2}$, suggesting the formation of $\mathrm{MnO}_{\mathrm{x}}$. The EDS analysis and EELS chemical mapping results (Fig. 6j-n) further confirm the formation of $\mathrm{MnO}_{\mathrm{x}}$ on the $\mathrm{h}-\mathrm{WO}_{3}$ nanowire. However, no sponge-like manganese oxide particles were found on the thick o- $\mathrm{WO}_{3} \cdot 0.33 \mathrm{H}_{2} \mathrm{O}$ nanorod, as shown in Fig. S5e and f. The Pt and $\mathrm{MnO}_{\mathrm{x}}$ photo-deposition experiments further prove the existence of phase junction in the WNC-2 and the photo-generated electrons transfer from $\mathrm{h}-\mathrm{WO}_{3}$ nanowire to $\mathrm{o}-\mathrm{WO}_{3} \cdot 0.33 \mathrm{H}_{2} \mathrm{O}$ nanorod and the holes move in the opposite direction. 
To more deeply study the energy band position of the vertical phase junction, UV-Vis absorption spectra, Mott-Schottky plots and XPS valence band spectra were studied. Fig. 7a shows that the light absorption both in the UV light and visible light region are enhanced as the amount of $\mathrm{NaCl}$ increases and the different absorption edges indicate the different band gaps of the samples. The inset in Fig. 7a gives the band gaps of the pure o- $\mathrm{WO}_{3} \cdot 0.33 \mathrm{H}_{2} \mathrm{O}(\mathrm{WNC}-1,2.74 \mathrm{eV})$ and pure $\mathrm{h}-\mathrm{WO}_{3}(\mathrm{WNC}-4,2.85 \mathrm{eV})$. The conduction band minimum position $\left(\mathrm{E}_{\mathrm{CBM}}\right)$ for $\mathrm{o}-\mathrm{WO}_{3} \cdot 0.33 \mathrm{H}_{2} \mathrm{O}$ and h- $\mathrm{WO}_{3}$ can be estimated by the Mott-Schottky plots. As shown in Fig. $7 \mathrm{~b}$, the flat band potential $\left(\mathrm{E}_{\mathrm{fb}}\right)$ for $\mathrm{o}-\mathrm{WO}_{3} \cdot 0.33 \mathrm{H}_{2} \mathrm{O}$ and $\mathrm{h}-\mathrm{WO}_{3}$ were -0.18 and $-0.31 \mathrm{~V}$ vs. SCE $(\mathrm{pH}=7)$, respectively. For n-type semiconductors, the $\mathrm{E}_{\mathrm{CBM}}$ is $0.1-0.3 \mathrm{~V}$ higher than that of $\mathrm{E}_{\mathrm{fb}}$ (take $0.2 \mathrm{~V}$ in this paper).[43] Therefore, the $\mathrm{E}_{\mathrm{CBM}}$ of $\mathrm{o}-\mathrm{WO}_{3} \cdot 0.33 \mathrm{H}_{2} \mathrm{O}$ and $\mathrm{h}-\mathrm{WO}_{3}$ at normal hydrogen electrode $(\mathrm{NHE}, \mathrm{pH}=0)$ can be calculated using the following equation:

$\mathrm{E}_{\mathrm{CBM}}(\mathrm{NHE}, \mathrm{pH}=0)=\mathrm{E}_{\mathrm{fb}}(\mathrm{SCE}, \mathrm{pH}=7)+0.24+0.0591 * \mathrm{pH}-0.2$

The results reveal that the $\mathrm{E}_{\mathrm{CBM}}$ of $\mathrm{o}-\mathrm{WO}_{3} \cdot 0.33 \mathrm{H}_{2} \mathrm{O}$ and $\mathrm{h}-\mathrm{WO}_{3}$ were about +0.27 and $+0.14 \mathrm{~V}$ vs. NHE, respectively. Considering the band gaps $(2.74$ and $2.85 \mathrm{eV})$, the valence band maximum position $\left(\mathrm{E}_{\mathrm{VBM}}\right)$ of $\mathrm{o}-\mathrm{WO}_{3} \cdot 0.33 \mathrm{H}_{2} \mathrm{O}$ and $\mathrm{h}-\mathrm{WO}_{3}$ were estimated to be +3.01 and $+2.99 \mathrm{~V}$ vs. NHE, respectively. The schematic diagram of energy level of $\mathrm{o}-\mathrm{WO}_{3} \cdot 0.33 \mathrm{H}_{2} \mathrm{O}$ and $\mathrm{h}-\mathrm{WO}_{3}$ was summarized in Fig. 7d. The $\mathrm{E}_{\mathrm{CBM}} / \mathrm{E}_{\mathrm{VBM}}$ of $\mathrm{o}-\mathrm{WO}_{3} \cdot 0.33 \mathrm{H}_{2} \mathrm{O}$ and $\mathrm{h}-\mathrm{WO}_{3}$ were evaluated to be $+0.27 /+3.01 \mathrm{~V}$ and $+0.14 /+2.99 \mathrm{~V}$, respectively. It was clear that the $\mathrm{VBM}$ of $\mathrm{o}-\mathrm{WO}_{3} \cdot 0.33 \mathrm{H}_{2} \mathrm{O}$ was lower than that of h- $\mathrm{WO}_{3}$. This result could be further confirmed by XPS valence band spectra, as shown in Fig. 7c. From the analysis above, it was known that the $\mathrm{CBM}$ of $\mathrm{o}-\mathrm{WO}_{3} \cdot 0.33 \mathrm{H}_{2} \mathrm{O}$ were lower than $\mathrm{h}-\mathrm{WO}_{3}$, while the VBM was deeper than that of $\mathrm{h}-\mathrm{WO}_{3}$. The relative energy band position of the two phases causes the photo-generated electrons transfer from $\mathrm{h}-\mathrm{WO}_{3}$ nanowire to o- $\mathrm{WO}_{3} \cdot 0.33 \mathrm{H}_{2} \mathrm{O}$ nanorod and 
the holes movement in the opposite direction. As a result, $\mathrm{Pt}$ and $\mathrm{MnO}_{\mathrm{x}}$ were selectively photo-deposited on o- $\mathrm{WO}_{3} \cdot 0.33 \mathrm{H}_{2} \mathrm{O}$ and h- $\mathrm{WO}_{3}$, respectively.

\subsection{Photocatalytic properties.}

Photocatalytic experiments were conducted to evaluate the photocatalytic activities of the tungsten oxides. Fig. 8a and $\mathrm{c}$ show the photodegradation of $\mathrm{RhB}$ and $\mathrm{MO}$ by the tungsten oxides. The corresponding rate constants $(\mathrm{k})$, which were calculated from the pseudo-first-order linear fitting results of Fig. S6a and b, and the rate constants per specific surface area $\left(\mathrm{k} / \mathrm{S}_{\mathrm{BET}}\right)$ were also presented in Fig. $8 \mathrm{~b}$ and d. Fig. 8a shows that only $62 \%$ and $52 \% \mathrm{RhB}$ can be degraded by pure $\mathrm{o}-\mathrm{WO}_{3} \cdot 0.33 \mathrm{H}_{2} \mathrm{O}$ (WNC-1) and pure $\mathrm{h}-\mathrm{WO}_{3}$ (WNC-4), while WNC-2 and WNC-3 with vertical $\mathrm{o}-\mathrm{WO}_{3} \cdot 0.33 \mathrm{H}_{2} \mathrm{O} / \mathrm{h}-\mathrm{WO}_{3}$ phase junction could degrade $92 \%$ and $81 \% \mathrm{RhB}$. WNC-2 performs best in degrading $\mathrm{RhB}$ with the $\mathrm{k}$ of 2.5 and 2.8 times and the $\mathrm{k} / \mathrm{S}_{\mathrm{BET}}$ of 2.6 and 4.3 times as high as those of WNC-1 and WNC-4, respectively. Similarly, as for photodegrading MO, WNC-2 and WNC-3 perform better than WNC-1 and WNC-4, as shown in Fig. 8c-d. The WNC-2 has the most excellent performance in degrading $\mathrm{MO}$, with the $\mathrm{k}$ of 2.7 and 11.4 times and the $\mathrm{k} / \mathrm{S}_{\mathrm{BET}}$ of 2.8 and 17.3 times as high as those of WNC-1 and WNC-4, respectively.

To eliminate the effect of dye self-sensitization on the photocatalytic activity, colorless phenol was further adopted as the pollutant target. Fig. 9 shows the photo-degradation activities and the corresponding rate constants $\mathrm{k}$ and $\mathrm{k} / \mathrm{S}_{\mathrm{BET}}$. WNC-2 and WNC-3 can photodegrade $52 \%$ and $44 \%$ phenol (10 mg/L), respectively. While only $38 \%$ and $17 \%$ phenol can be degraded by pure o- $\mathrm{WO}_{3} \cdot 0.33 \mathrm{H}_{2} \mathrm{O}(\mathrm{WNC}-1)$ and pure $\mathrm{h}-\mathrm{WO}_{3}(\mathrm{WNC}-4)$, respectively, as shown in Figure $9 \mathrm{a}$. Both the 
$\mathrm{k}$ and $\mathrm{k} / \mathrm{S}_{\mathrm{BET}}$ of WNC-2 are highest among the four samples, as shown in Fig. 9b. In addition to dyes, the photodegradation of phenol confirms the superior photocatalytic performance of WNC-2 and WNC-3. To sum up, as for photodegrading dyes or phenol, the phase-junction samples perform better than the pure phases and the sample with more o- $\mathrm{WO}_{3} \cdot 0.33 \mathrm{H}_{2} \mathrm{O}$ in the phase junction (WNC-2) shows higher photocatalytic performance than the sample with less o- $\mathrm{WO}_{3} \cdot 0.33 \mathrm{H}_{2} \mathrm{O}(\mathrm{WNC}-3)$.

The stability of photocatalyst was also studied. Fig. 10 shows that WNC-2 has a good recyclability in degrading $\mathrm{RhB}$ with only a small decline of activity after four cycles. The crystal structure of WNC-2 was unchanged after phtotocatalysis test, as shown in Fig. S7. Moreover, WNC-2 can maintain the appearance of sunflower-like structure, and the nanowires and nanorods keep their original structures after photocatalysis (Fig. S8). These all suggest that the as-prepared photocatalysts have good structure stability.

Since the specific surface areas of WNC-1, WNC-2, WNC-3 and WNC-4 (Table S1) show an increasing trend, while the plots of $\mathrm{k} / \mathrm{S}_{\mathrm{BET}}$ show similar variation to those of $\mathrm{k}$ (Fig. $8 \mathrm{~b}$ and $\mathrm{d}$ and Fig. $9 b$ ), the specific surface area should not be the main factor for the variation of photocatalytic performance. The results of photodegrading RhB, MO and phenol all show that the samples WNC-2 and WNC-3 with vertical o- $\mathrm{WO}_{3} \cdot 0.33 \mathrm{H}_{2} \mathrm{O} / \mathrm{h}-\mathrm{WO}_{3}$ phase junction show better perfomance than the pure phases. It is believed that the synergetic effect between the two phases is the key factor that influences the photocatalytic performance. Moreover, the sample (WNC-2) with less $\mathrm{h}-\mathrm{WO}_{3}$ in the phase-junction tungsten oxide shows better photocatalytic property than the sample (WNC-3) which contains more $\mathrm{h}-\mathrm{WO}_{3}$, implying that a lower proportion of $\mathrm{h}-\mathrm{WO}_{3}$ in the phase-junction tungsten 
oxide is favourable for strengthening its photocatalytic capability. In summary, the construction of vertical $1 \mathrm{D} \mathrm{o}-\mathrm{WO}_{3} \cdot 0.33 \mathrm{H}_{2} \mathrm{O} / \mathrm{h}-\mathrm{WO}_{3}$ phase junction, especially the phase junction with more $\mathrm{o}-\mathrm{WO}_{3} \cdot 0.33 \mathrm{H}_{2} \mathrm{O}$, in the tungsten oxides could significantly improve the photocatalytic performance.

\subsection{The mechanism for the enhanced photocatalytic performance.}

The separation and transfer efficiency of photogenerated electrons and holes has a significant influence on the photocatalytic performance.[44] The photoelectrochemical performances of the samples were studied using photocurrent-time curves and the electrochemical impedance spectra (EIS). Fig. 11a shows that WNC-2 and WNC-3 with vertical o- $\mathrm{WO}_{3} \cdot 0.33 \mathrm{H}_{2} \mathrm{O} / \mathrm{h}-\mathrm{WO}_{3}$ phase junction have higher photocurrent density than the pure o- $\mathrm{WO}_{3} \cdot 0.33 \mathrm{H}_{2} \mathrm{O}(\mathrm{WNC}-1)$ and h- $\mathrm{WO}_{3}(\mathrm{WNC}-4)$, suggesting that the phase junction can promote the quick separation and transfer of the photogenerated charges. Moreover, the $\mathrm{WNC}-2$ with a lower proportion of $\mathrm{h}-\mathrm{WO}_{3}$ in the phase-junction tungsten oxide shows higher photocurrent density than that of WNC-3. The variation of the photocurrent agrees well with that of the photocatalytic performance. The EIS were measured both in the dark and under simulated solar light irradiation, as shown in Fig. 11b. The arc radius on the EIS spectra reflects the solid state interface layered resistance and the surface charges transfer resistance. WNC-2 and WNC-3 with o- $\mathrm{WO}_{3} \cdot 0.33 \mathrm{H}_{2} \mathrm{O} / \mathrm{h}-\mathrm{WO}_{3}$ phase junction exhibit smaller arc radii than the pure o- $\mathrm{WO}_{3} \cdot 0.33 \mathrm{H}_{2} \mathrm{O}(\mathrm{WNC}-1)$ and $\mathrm{h}-\mathrm{WO}_{3}(\mathrm{WNC}-4)$, also confirming the faster transfer of photogenerated charges. Both in the dark and under simulated solar light irradiation, WNC-2 has the smallest arc radii, suggesting that the reaction rate on this electrode surface is the maximum and the electrode resistance is the smallest, so the separation and transfer of photogenerated electrons and holes in WNC-2 is the fastest. To further demonstrate the efficient separation of photogenerated electrons and holes over the phase junction, PL spectra were measured as shown in Fig. S9. The four 
samples all show the main PL peak at about $445 \mathrm{~nm}$, which is related to the recombination of photogenerated electrons and holes.[45] Both WNC-2 and WNC-3 show a weaker PL signal than the pure phases, suggesting that the phase junction could reduce the recombination rate of the photogenerated electrons and holes. Especially, WNC-2 has a lower PL signal than WNC-3, once again proving a lower recombination rate of photo-generated electrons and holes in the sample with lower amount of $\mathrm{h}-\mathrm{WO}_{3}$. In summary, the vertical o- $\mathrm{WO}_{3} \cdot 0.33 \mathrm{H}_{2} \mathrm{O} / \mathrm{h}-\mathrm{WO}_{3}$ phase junction, especially the phase junction with a lower proportion of $\mathrm{h}-\mathrm{WO}_{3}$, would lead to a high separation efficiency of photogenerated carriers, thus resulting in the high efficiency of photodegrading $\mathrm{RhB}$, MO and phenol.

In order to further study the photodegradation mechanism, the trapping experiments using t-BuOH $\left(\cdot \mathrm{OH}\right.$ scavenger),[44] EDTA-2Na (hole scavenger)[44] and p-benzoquinone $\left(\cdot \mathrm{O}_{2}-\right.$ scavenger) [46]were carried out, as shown in Fig. 12a and b. The process of photodegrading RhB over WNC-2 could be impeded by adding EDTA-2Na and t-BuOH, and the addition of p-benzoquinone can cause a bigger decrease on the photocatalytic performance, as shown in Fig.12a. But neither of them greatly reduces the photocatalytic performance. This suggests that $\bullet \mathrm{O}_{2^{-}}$, holes and $\bullet \mathrm{OH}$ are all contributed to the process of photodegrading RhB. Similarly, the performance of photodegrading MO over the same sample decreases obviously after adding p-benzoquinone (Fig.12b). The addition of EDTA-2Na and t-BuOH can also cause distinct but more moderate decline of the performance. This demonstrates that $\bullet \mathrm{O}_{2^{-}}$, holes and $\bullet \mathrm{OH}$ are all involved in the process of photodegrading MO. It seems that the conduction band edges of the as-prepared samples (Fig.7d) are not feasible to produce $\cdot \mathrm{O}_{2^{-}}$. However, some researchers also reported the generation of $\bullet \mathrm{O}_{2^{-}}$by the photocatalysts with 
similar conduction band edge, and in some cases, $\bullet \mathrm{O}_{2}$ - can be the main reactive species.[46,47] Since the band gap of $\mathrm{WO}_{3}$ is about $2.8 \mathrm{eV}$, under $\lambda \leq 443 \mathrm{~nm}$ light irradiation, some electrons can be excited to be more negative potentials than the CBM to react with oxygen to generate superoxide radicals.[47]. Moreover, tungsten oxide with rich defects ensures the chemisorption of molecular

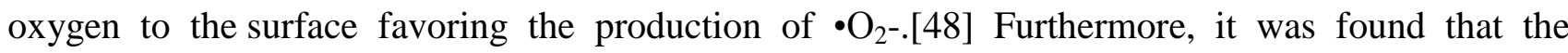
tungsten oxide with different morphology had different main reactive species and $\bullet \mathrm{O}_{2}$ - was the main reactive species for the nanorods.[49] To confirm the results of the trapping experiments, ESR was used to detect the $\bullet \mathrm{O}_{2}$ - and $\bullet \mathrm{OH}$, as shown in Fig. 12c and d. The characteristic four peaks of $\bullet \mathrm{OH}$ adducts with intensity $1: 2: 2: 1$ and the six characteristic peaks of the $\cdot \mathrm{O}_{2}$ - adducts clearly suggest the generation of $\bullet \mathrm{OH}$ and $\bullet \mathrm{O}_{2}$ - radicals.

Based on the discussion above, the schemes of the sunflower-like tungsten oxide, the structure of the vertical phase junction and the corresponding charges separation and transfer are proposed in Fig. 13. Upon irradiation of the sunflower-like tungsten oxide hierarchical structure (Fig. 13I) containing vertical $\mathrm{o}-\mathrm{WO}_{3} \cdot 0.33 \mathrm{H}_{2} \mathrm{O}$ nanorods $/ \mathrm{h}-\mathrm{WO}_{3}$ nanowires phase junction (Fig. 13II), the photogenerated electrons tend to transfer from the h- $\mathrm{WO}_{3}$ nanowires to the $\mathrm{o}-\mathrm{WO}_{3} \cdot 0.33 \mathrm{H}_{2} \mathrm{O}$ nanorods, while the photogenerated holes transfer from the o- $\mathrm{WO}_{3} \cdot 0.33 \mathrm{H}_{2} \mathrm{O}$ nanorods to the $\mathrm{h}-\mathrm{WO}_{3}$ nanowires, driven by the potential difference caused by the different band levels of o- $\mathrm{WO}_{3} \cdot 0.33 \mathrm{H}_{2} \mathrm{O}$ and h-WO $\mathrm{WO}_{3}$ (Fig. 13III). Thus, the photogenerated electrons and holes can be spatially separated into two different phases and thus charge recombination is drastically inhibited and both the separated electrons and holes can contact the pollutants to play their roles, which greatly benefit the photocatalytic reaction. In addition, from the TEM images, the two phases are both single crystals. 
The much lower defects in comparison with multi-crystals favour the transport of the charge carriers.[20,50]

\section{Conclusion}

The sunflower-like tungsten oxide hierarchical structures were synthesized via a one-step hydrothermal method by adjusting the amount of $\mathrm{NaCl}$. It is found that the sunflower-like tungsten oxide hierarchical structures are assembled with $\mathrm{o}-\mathrm{WO}_{3} \cdot 0.33 \mathrm{H}_{2} \mathrm{O}$ nanorods in the outer region and $\mathrm{h}-\mathrm{WO}_{3}$ nanowires in the centre region. The nanorods and nanowires substantially perpendicularly intersect at the endpoint. The XRD patterns, Raman spectra, SEM images, HRTEM images and Pt and $\mathrm{MnO}_{\mathrm{x}}$ loading experiments suggest that the vertical o- $\mathrm{WO}_{3} \cdot 0.33 \mathrm{H}_{2} \mathrm{O}$ nanorods $/ \mathrm{h}-\mathrm{WO}_{3}$ nanowires phase junctions are successfully constructed in this structure. The energy band position of the samples were also carefully studied and the results show that the $\mathrm{CBM}$ of $\mathrm{o}-\mathrm{WO}_{3} \cdot 0.33 \mathrm{H}_{2} \mathrm{O}$ were lower than $\mathrm{h}-\mathrm{WO}_{3}$ and the $\mathrm{VBM}$ was deeper than $\mathrm{h}-\mathrm{WO}_{3}$, suggesting that the electrons transfer from $\mathrm{h}-\mathrm{WO}_{3}$ to $\mathrm{o}-\mathrm{WO}_{3} \cdot 0.33 \mathrm{H}_{2} \mathrm{O}$ and the holes move in the opposite direction under light irradiation. The photocatalytic performance can be greatly enhanced by the vertical phase junction and the sample with lower amount of $\mathrm{h}-\mathrm{WO}_{3}$ in the phase-junction tungsten oxide shows excellent photocatalytic properties. The results of photoelectrochemical performances show that the vertical $\mathrm{o}-\mathrm{WO}_{3} \cdot 0.33 \mathrm{H}_{2} \mathrm{O} / \mathrm{h}-\mathrm{WO}_{3}$ phase junction would significantly increase the separation efficiency of photogenerated charges.

\section{Acknowledgment}

This work was supported by the National Basic Research Program of China (973 Program) (No. 2013CB934301), the National Science Foundation of China (Grant No. 51472013 and 51672016), 
the State Key Laboratory of New Ceramic and Fine Processing Tsinghua University (No. KF201602) and the Beijing Key Discipline Foundation of Condensed Matter Physics.

\section{Supporting Information}

SEM images of WNC-1 and WNC-4; Lower magnification TEM images of WNC-2 and WNC-3; XRD patterns, XPS spectra, SEM images and TEM images of WCN-2 after photo-depositing Pt particles and after photo-depositing MnOx particles; pseudo-first-order linear fitting results; specific surface areas of the samples; XRD patterns, SEM images and TEM images of WCN-2 after photocatalysis; room temperature PL spectra. This information is available free of charge via the Internet at http://pubs.acs.org.

\section{References:}

[1] S. Wang, X. Wang, Angew. Chem. Int. Edit. 55 (2016) 2308-2320.

[2] F. Cao, J. Xiong, F. Wu, Q. Liu, Z. Shi, Y. Yu, X. Wang, L. Li, ACS Appl. Mater. Interfaces 8 (2016) 12239-12245.

[3] S. Wang, X. Wang, Small 11 (2015) 3097-3112.

[4] R. Kuriki, K. Sekizawa, O. Ishitani, K. Maeda, Angew. Chem. Int. Edit. 54 (2015) 2406-2409.

[5] S. Wang, Z. Ding, X. Wang, Chem. Commun. 51 (2015) 1517-1519.

[6] Y. Lu, G. Liu, J. Zhang, Z. Feng, C. Li, Z. Li, Chinese J. Catal. 37 (2016) 349-358.

[7] S. Wang, W. Yao, J. Lin, Z. Ding, X. Wang, Angew. Chem. Int. Edit. 53 (2014) 1034-1038.

[8] S. Wang, X. Wang, Appl. Catal. B: Environ. 162 (2015) 494-500.

[9] Y. Ma, X. Wang, C. Li, Chinese J. Catal. 36 (2015) 1519-1527.

[10] Y. Zhu, Y. Liu, Y. Lv, Q. Ling, D. Liu, Y. Zhu, J. Mater. Chem. A 2 (2014) 13041-13048.

[11]Z. Huang, Q. Sun, K. Lv, Z. Zhang, M. Li, B. Li, Appl. Catal. B: Environ. 164 (2015) 420-427. 
[12]K. Maeda, K. Ishimaki, Y. Tokunaga, D. Lu, M. Eguchi, Angew. Chem. Int. Edit. 55 (2016) 8309-8313.

[13]A. Li, Z. Wang, H. Yin, S. Wang, P. Yan, B. Huang, X. Wang, R. Li, X. Zong, H. Han, C. Li, Chem. Sci. 7 (2016) 6076-6082.

[14]W. Wang, J. Chen, X. Zhang, Y. Huang, W. Li, H. Yu, Sci. Rep-UK 6 (2016) 20491.

[15]W. Wang, J. Chen, M. Gao, Y. Huang, X. Zhang, H. Yu, Appl. Catal. B: Environ. 195 (2016) 69-76.

[16]S. Zhu, S. Xie, Z. Liu, J. Am. Chem. Soc. 137 (2015) 11532-11539.

[17]L. Pan, H. Huang, C. Lim, Q. Hong, M. Tse, O. Tan, RSC Adv. 3 (2013) 3566-3571.

[18]B. Liu, A. Khare, E.S. Aydil, ACS Appl. Mater. Interfaces 3 (2011) 4444-4450.

[19]G. Liu, X. Yan, Z. Chen, X. Wang, L. Wang, G.Q. Lu, H. Cheng, J. Mater. Chem. 19 (2009) 6590-6596.

[20]W. Li, C. Liu, Y. Zhou, Y. Bai, X. Feng, Z. Yang, L. Lu, X. Lu, K. Chan, J. Phys. Chem. C 112 (2008) 20539-20545.

[21]S. Jin, X. Wang, X. Wang, M. Ju, S. Shen, W. Liang, Y. Zhao, Z. Feng, H.Y. Playford, R.I. Walton, C. Li, J. Phys. Chem. C 119 (2015) 18221-18228.

[22]J. Liu, G. Zhang, Mater. Res. Bull. 68 (2015) 254-259.

[23]M. Ju, X. Wang, W. Liang, Y. Zhao, C. Li, J. Mater. Chem. A 2 (2014) 17005-17014.

[24]L. Shi, J. Zhang, S. Wu, Y. Li, L. Jiang, Q. Cui, J. Am. Ceram. Soc. 97 (2014) 2607-2614.

[25]X. Wang, Q. Xu, M. Li, S. Shen, X. Wang, Y. Wang, Z. Feng, J. Shi, H. Han, C. Li, Angew. Chem. Int. Edit. 51 (2012) 13089-13092.

[26] Y. Kong, H. Sun, X. Zhao, B. Gao, W. Fan, Appl. Catal. A-Gen. 505 (2015) 447-455. 
[27]X. Chen, Y. Zhou, Q. Liu, Z. Li, J. Liu, Z. Zou, ACS Appl. Mater. Interfaces 4 (2012) $3372-3377$.

[28]P. Yang, J. Zhao, J. Wang, B. Cao, L. Li, Z. Zhu, J. Mater. Chem. A 3 (2015) 8256-8259.

[29] Y. Liu, Q. Li, S. Gao, J.K. Shang, CrystEngComm 16 (2014) 7493-7501.

[30]J. Cao, B. Luo, H. Lin, B. Xu, S. Chen, Appl. Catal. B-Environ. 111 (2012) 288-296.

[31]F.X. Xiao, J.W. Miao, H.B. Tao, S.F. Hung, H.Y. Wang, H.B. Yang, J.Z. Chen, R. Chen, B. Liu, Small 11 (2015) 2115-2131.

[32]K. Li, M. Han, R. Chen, S. Li, S. Xie, C. Mao, X. Bu, X. Cao, L. Dong, P. Feng, Y. Lan, Adv. Mater. 3 (2016) 1-6.

[33]S. Khanchandani, S. Kundu, A. Patra, A.K. Ganguli, J. Phys. Chem. C 117 (2013) 5558-5567.

[34]S. Liu, N. Zhang, Z. Tang, Y. Xu, ACS Appl. Mater. Interfaces 4 (2012) 6378-6385.

[35]Y. Li, Z. Tang, J. Zhang, Z. Zhang, CrystEngComm 17 (2015) 9102-9110.

[36]C. Santato, M. Odziemkowski, M. Ulmann, J. Augustynski, J. Am. Chem. Soc. 123 (2001) 10639-10649.

[37]J. Wang, E. Khoo, P.S. Lee, J. Ma, J. Phys. Chem. C 113 (2009) 9655-9658.

[38]J. Wang, E. Khoo, P.S. Lee, J. Ma, J. Phys. Chem. C 112 (2008) 14306-14312.

[39]J. Yin, H. Cao, J. Zhang, M. Qu, Z. Zhou, Cryst. Growth Des. 13 (2013) 759-769.

[40]Q.H. Li, L.M. Wang, D.Q. Chu, X.Z. Yang, Z.Y. Zhang, Ceram. Int. 40 (2014) 4969-4973.

[41]A. Phuruangrat, D.J. Ham, S.J. Hong, S. Thongtem, J.S. Lee, J. Mater. Chem. 20 (2010) 1683-1690.

[42]L. Chen, S. Lam, Q. Zeng, R. Amal, A. Yu, J. Phys. Chem. C 116 (2012) 11722-11727.

[43]Z. Zhao, T. Butburee, M. Lyv, P. Peerakiatkhajohn, S. Wang, L. Wang, H. Zheng, RSC Adv. 6 
(2016) 68204-68210.

[44] Y. Lv, Y. Liu, Y. Zhu, Y. Zhu, J. Mater. Chem. A 2 (2014) 1174-1182.

[45]J. Sun, J. Guo, J. Ye, B. Song, K. Zhang, S. Bai, R. Luo, D. Li, A. Chen, J. Alloy Compd. 692 (2017) 876-884.

[46]J. Wang, W. Shi, D. Liu, Z. Zhang, Y. Zhu, D. Wang, Appl. Catal. B-Environ. 202 (2017) 289-297.

[47]X. Xiao, R. Hu, S. Tu, C. Zheng, H. Zhong, X. Zuo, J. Nan, RSC Adv. 5 (2015) 38373-38381.

[48]N. Zhang, X. Li, H. Ye, S. Chen, H. Ju, D. Liu, Y. Lin, W. Ye, C. Wang, Q. Xu, J. Zhu, L. Song, J. Jiang, Y. Xiong, J. Am. Chem. Soc. 138 (2016) 8928-8935.

[49]M. Farhadian, P. Sangpour, G. Hosseinzadeh, J. Energy Chem. 24 (2015) 171-177.

[50]G. Tian, H. Fu, L. Jing, B. Xin, K. Pan, J. Phys. Chem. C 112 (2008) 3083-3089.

\section{Caption of Figures}

Fig. 1 (a) XRD patterns of the tungsten oxides prepared with different amount of $\mathrm{NaCl}$; (b) XRD pattern fitting analysis of WNC-2; (c) the enlarged picture of WNC-3 at the range of $10-20^{\circ}$ and the corresponding XRD pattern fitting analysis (the inset).

Fig. 2 Raman spectra of the tungsten oxides prepared with different amount of $\mathrm{NaCl}(\mathrm{O}$ : Orthorhombic $\mathrm{WO}_{3} \cdot 0.33 \mathrm{H}_{2} \mathrm{O}, \mathrm{H}$ : Hexagonal $\mathrm{WO}_{3}$ ).

Fig. 3 SEM images of (a-c) WNC-2 with single sunflower-like structure and the corresponding enlarged picture of the rectangular region; (d-e) WNC-3 and the corresponding enlarged picture of the rectangular region; (f-h) a fractured sunflower-like structure (WNC-3) with the corresponding enlarged pictures of the rectangular region 1(R1) and region 2 (R2); (the arrows in Fig. $\mathrm{c}, \mathrm{e}, \mathrm{g}$ and $\mathrm{h}$ 
illustrate the vertical relation of the nanorods and nanowires); (i) the enlarged image of the center region of the sunflower-like tungsten oxide (WNC-2, WNC-3 and WNC-4 have similar morphology in this region).

Fig. 4 HRTEM images of (a) nanoplate in WNC-1, (b-c) nanorod and nanowire in WNC-2, (d-e) nanorod and nanowire in WNC-3 and (f) nanowire in WNC-4. (The TEM samples were prepared by sonicating for about $20 \mathrm{~min}$ for better observing the nanorods and nanowires.)

Fig. 5 Illustration of the morphology and crystal phase tuning of tungsten oxide by adjusting the amount of $\mathrm{NaCl}$.

Fig. 6 The typical TEM images, EDS analysis, BF-STEM and EELS chemical mapping of WNC-2 after photo-depositing (a-g) Pt on the $\mathrm{o}-\mathrm{WO}_{3} \cdot 0.33 \mathrm{H}_{2} \mathrm{O}$ nanorod or $(\mathrm{h}-\mathrm{n}) \mathrm{MnO}_{\mathrm{x}}$ on the $\mathrm{h}-\mathrm{WO}_{3}$ nanowire. (The TEM samples were prepared by sonicating for about $20 \mathrm{~min}$ for better observing the nanorods and nanowires.)

Fig. 7 (a) UV-Vis absorption spectra, the plot of $(\alpha h v)^{2}$ vs hv (the inset); (b) Mott-Schottky plots; (c) XPS valence band spectra and (d) band-edge positions of o- $\mathrm{WO}_{3} \cdot 0.33 \mathrm{H}_{2} \mathrm{O}$ and h- $\mathrm{WO}_{3}$.

Fig. 8 Photocatalytic degradation of (a-b) $\mathrm{RhB}$ and (c-d) MO in aqueous solution under simulated solar light irradiation in the presence of the various tungsten oxides ( $\mathrm{k}$ : the rate constants, calculated from the pseudo-first-order linear fitting results of Fig. S6a or b, k/S $\mathrm{S}_{\mathrm{BET}}$ : divided the rate constant by the specific surface area (Table S1)).

Fig. 9 (a) Photocatalytic degradation of phenol in aqueous solution under simulated solar light irradiation in the presence of the various tungsten oxides and (b) the corresponding column diagram of $\mathrm{k}$ and $\mathrm{k} / \mathrm{S}_{\mathrm{BET}}$.

Fig. 10 The recyclability of the vertical o- $\mathrm{WO}_{3} \cdot 0.33 \mathrm{H}_{2} \mathrm{O} / \mathrm{h}-\mathrm{WO}_{3}$ phase junction (WNC-2). 
Figure 11 (a) Photocurrent responses and (b) Nyquist plots of the samples.

Fig. 12 The plots of photogenerated charges trapping in the system of photodegradation of (a) RhB or (b) MO over WNC-2 under simulated solar light irradiation; ESR signals of (c) the $\bullet \mathrm{O}_{2}$ - in the methanol and (b) the $\cdot \mathrm{OH}$ in the aqueous dispersion under simulated solar light at room temperature. Fig. 13 The illustration of (I) sunflower-like tungsten oxide hierarchical structure, (II) the phase junction constructed by the vertical intersected o- $\mathrm{WO}_{3} \cdot 0.33 \mathrm{H}_{2} \mathrm{O}$ nanorods and $\mathrm{h}-\mathrm{WO}_{3}$ nanowires and (III) the energy band position of the phase junction (CB: conduction band, VB: valence band, the charges separation and transfer are also illustrated in the (II and III)). 

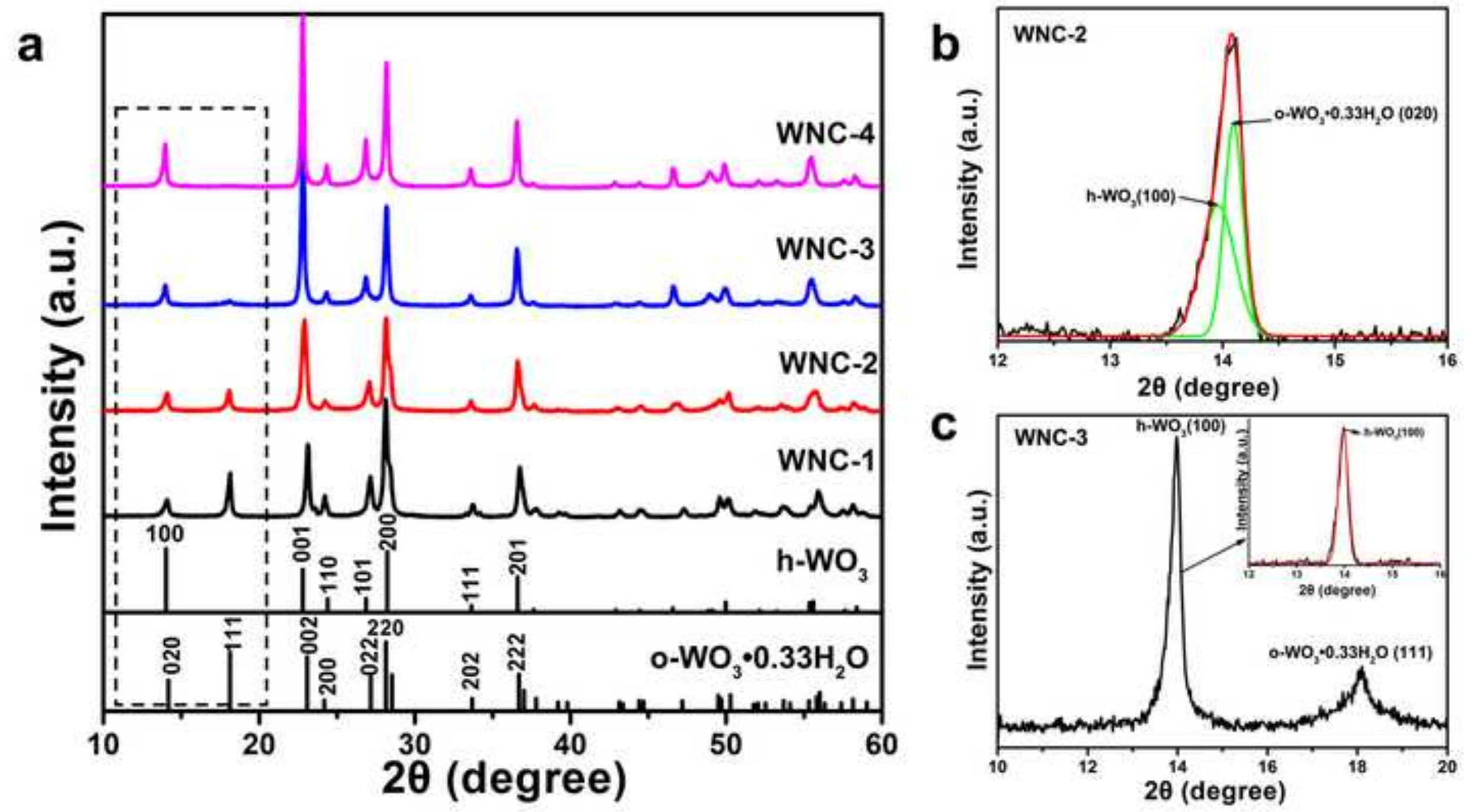


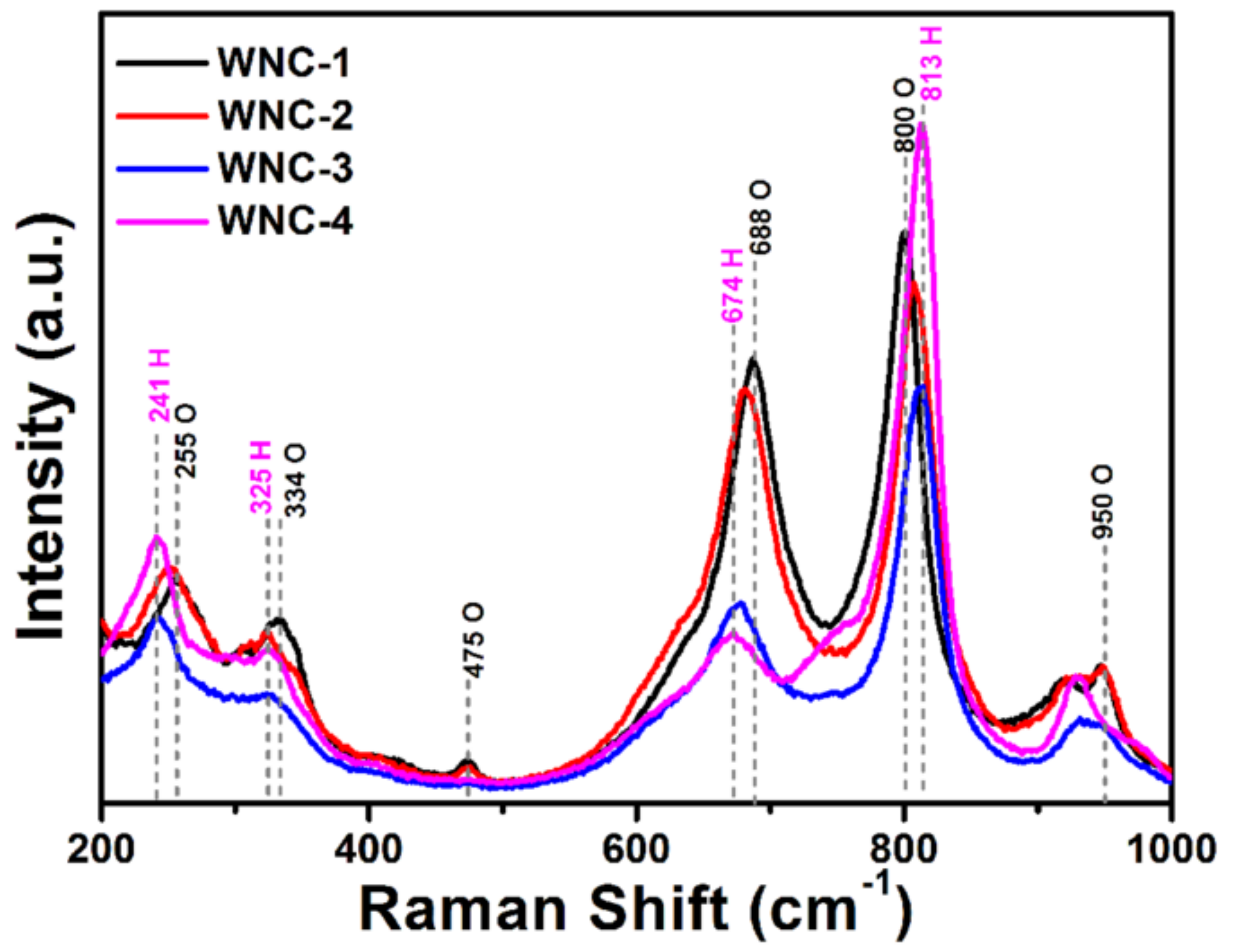



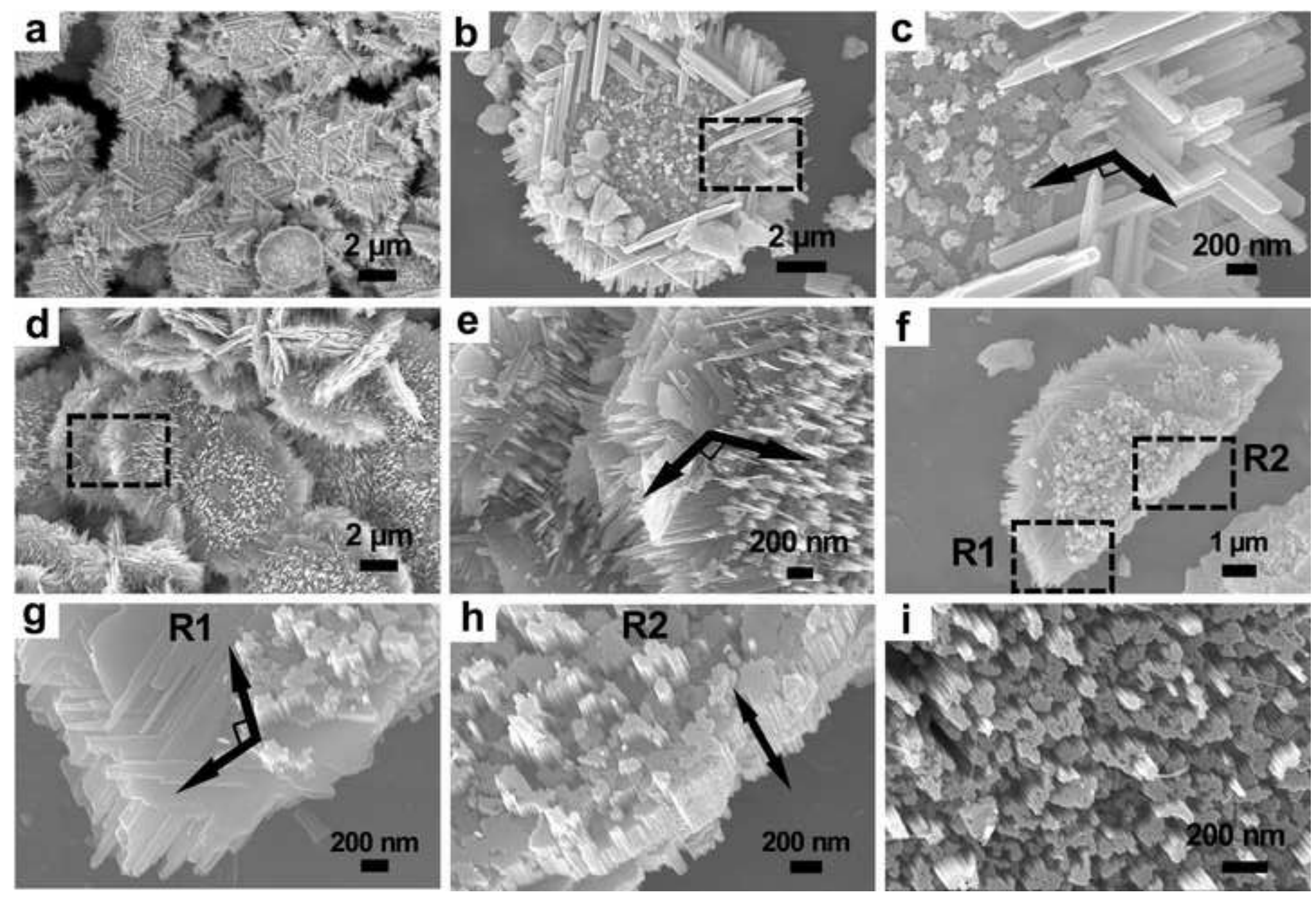

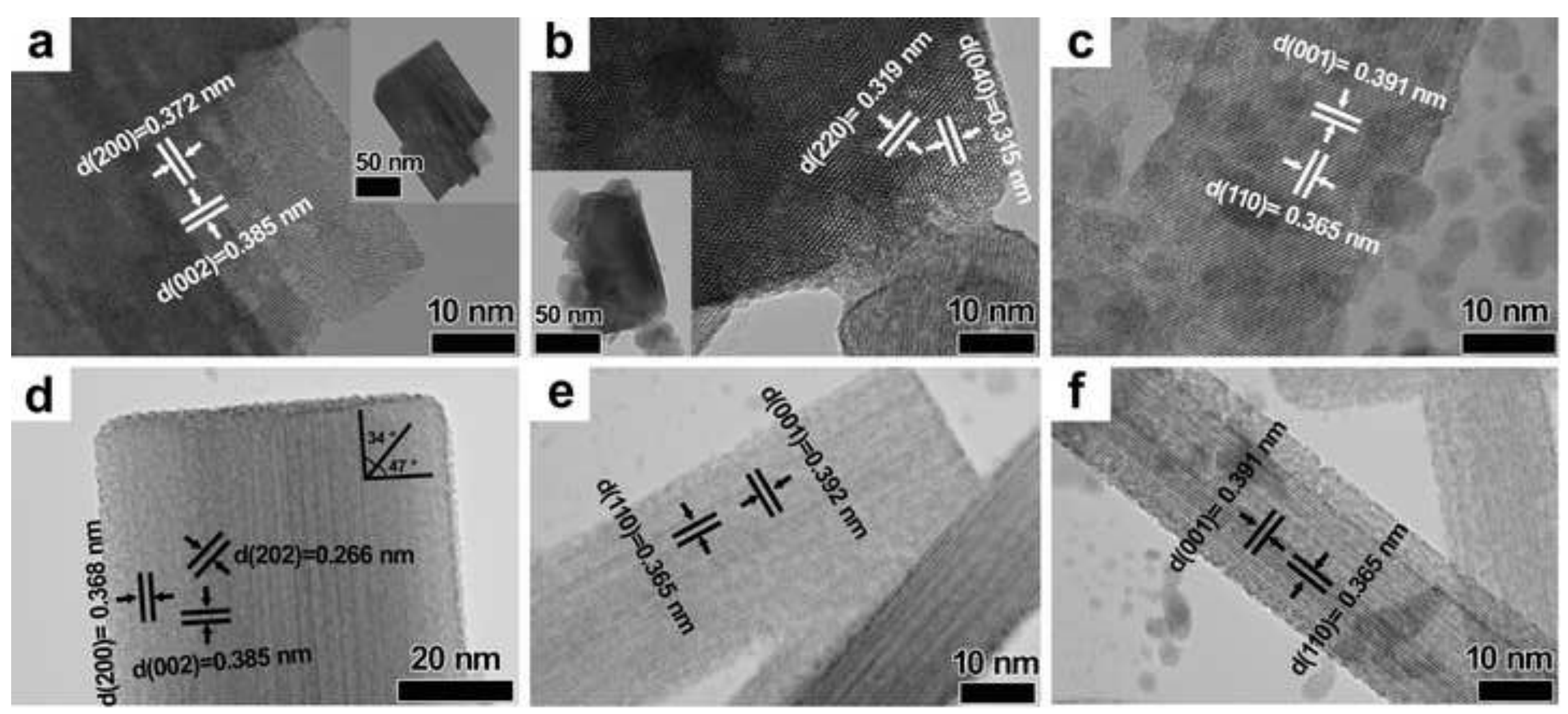


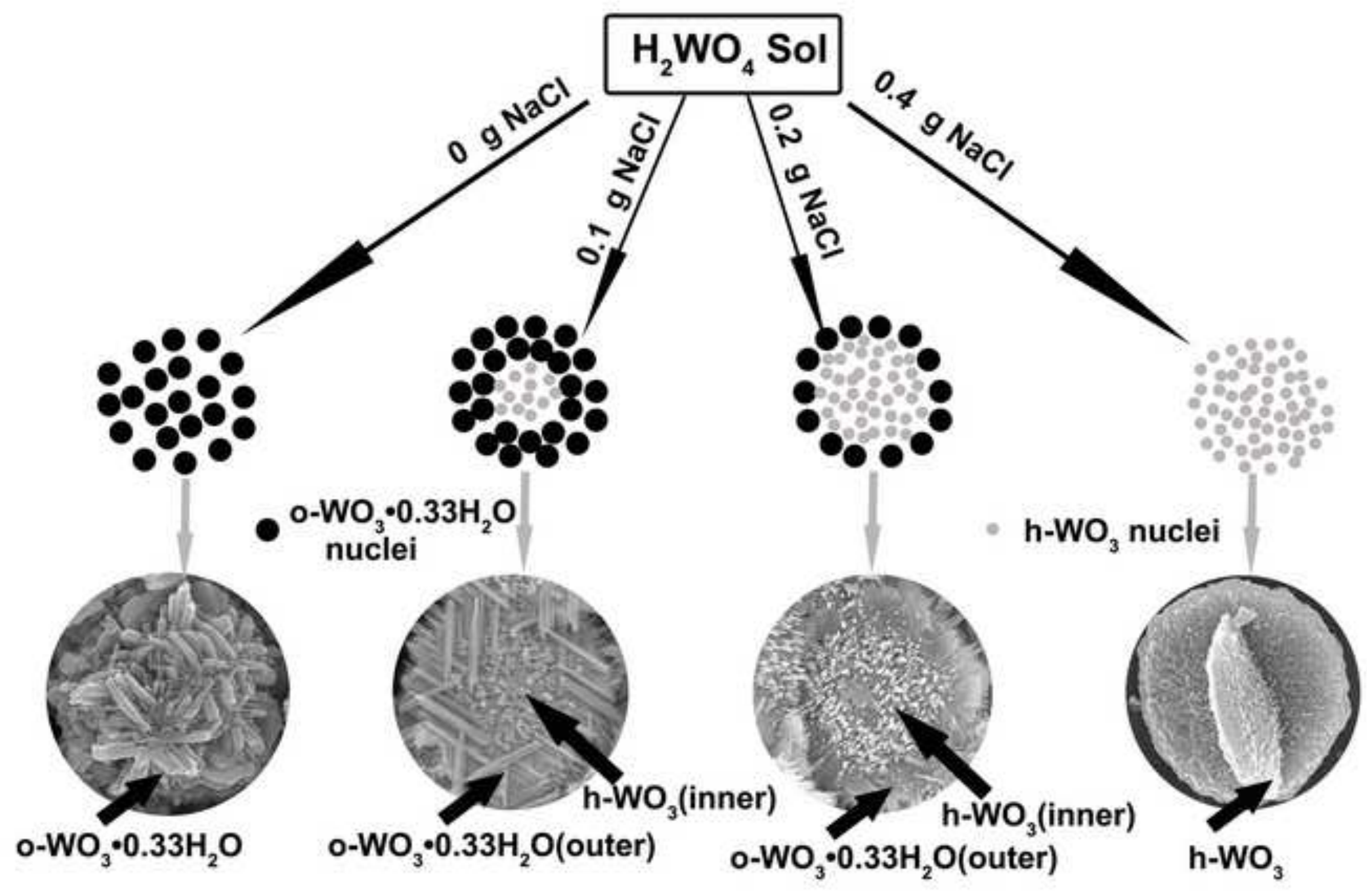



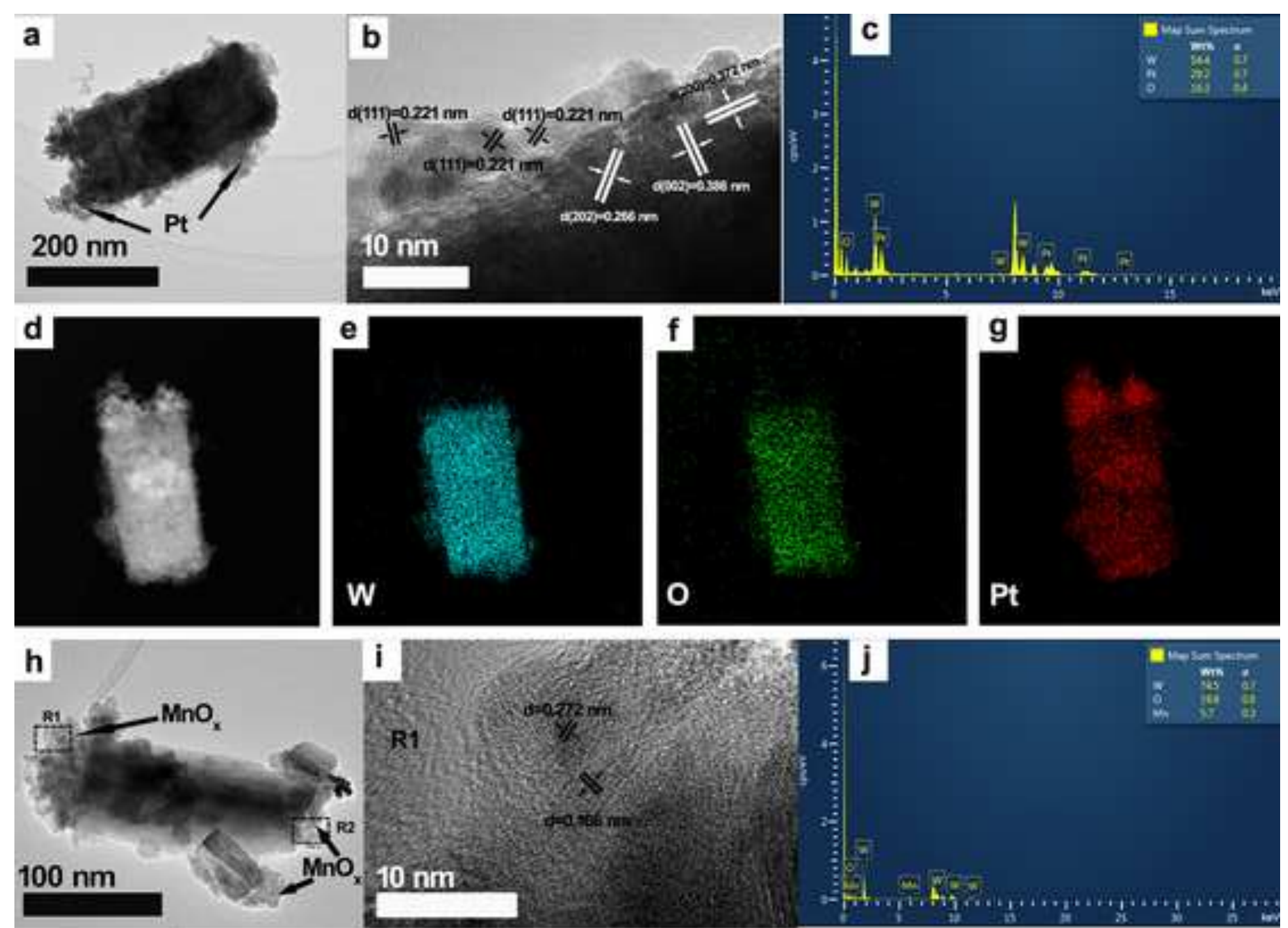

Pt
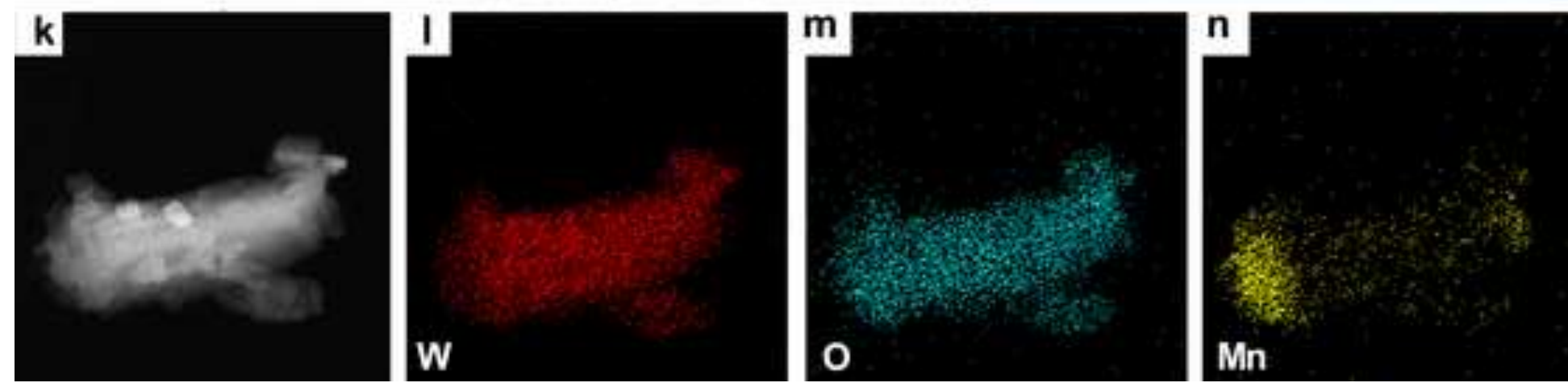

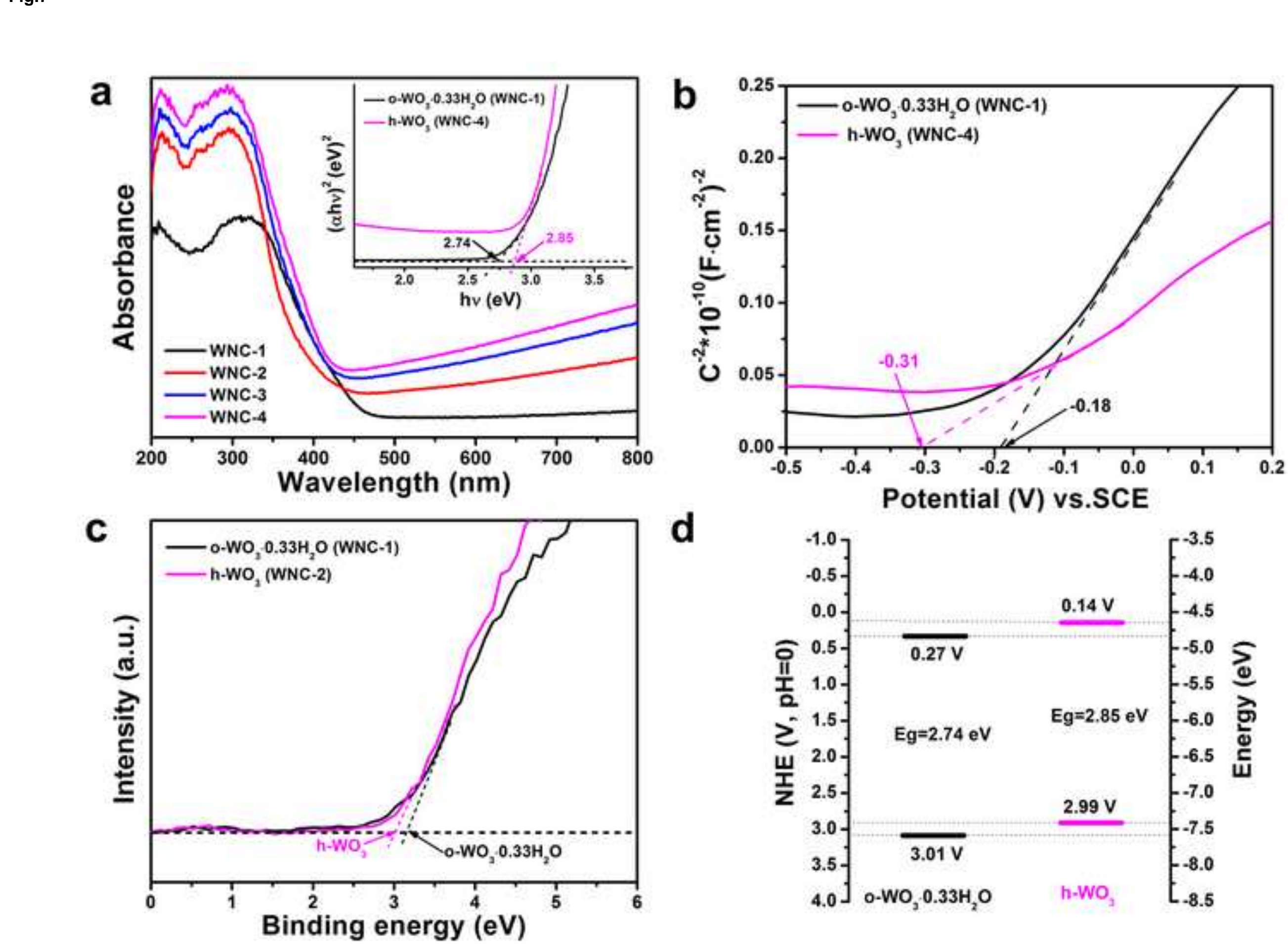

d 

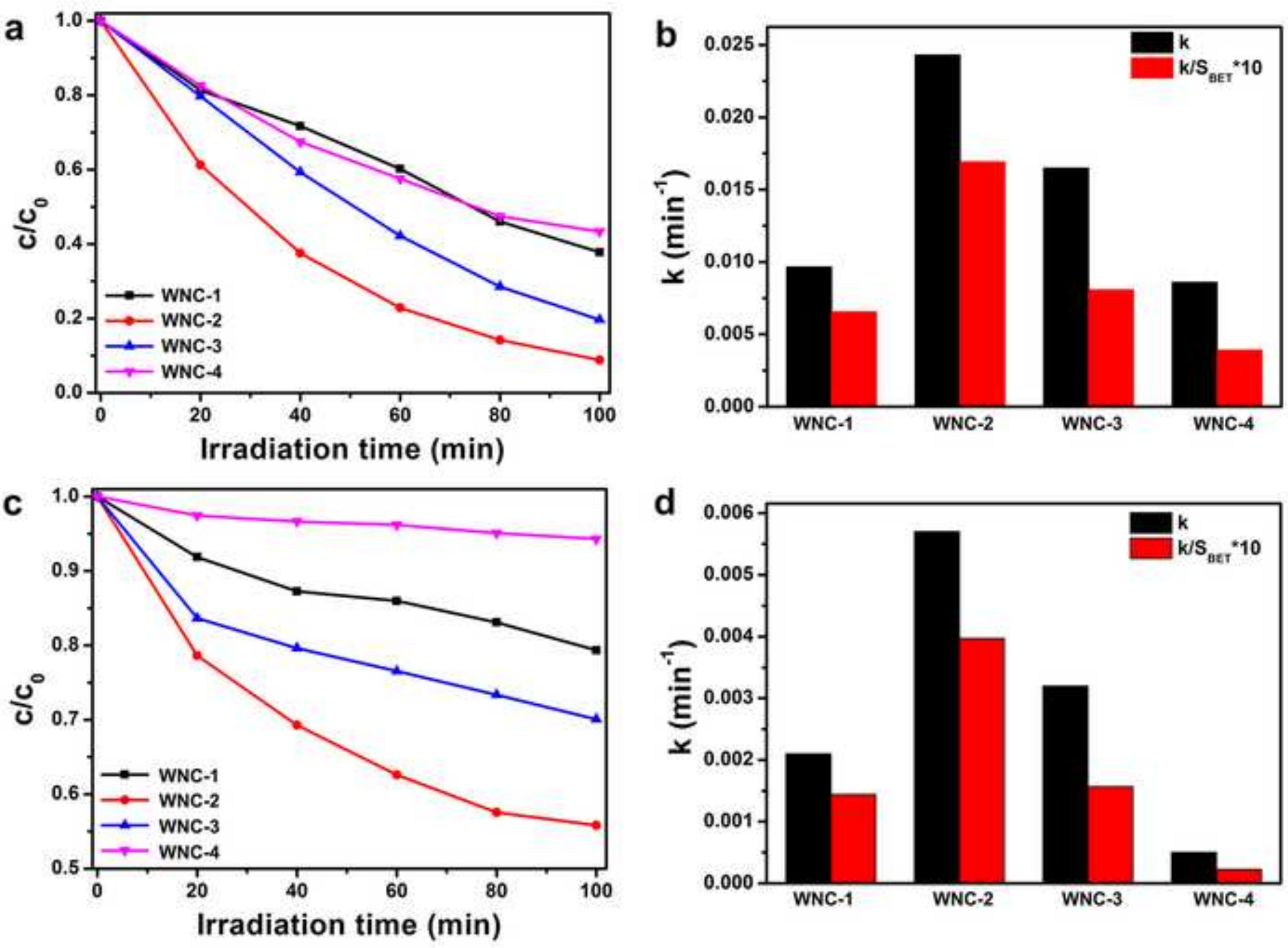
Fig.9
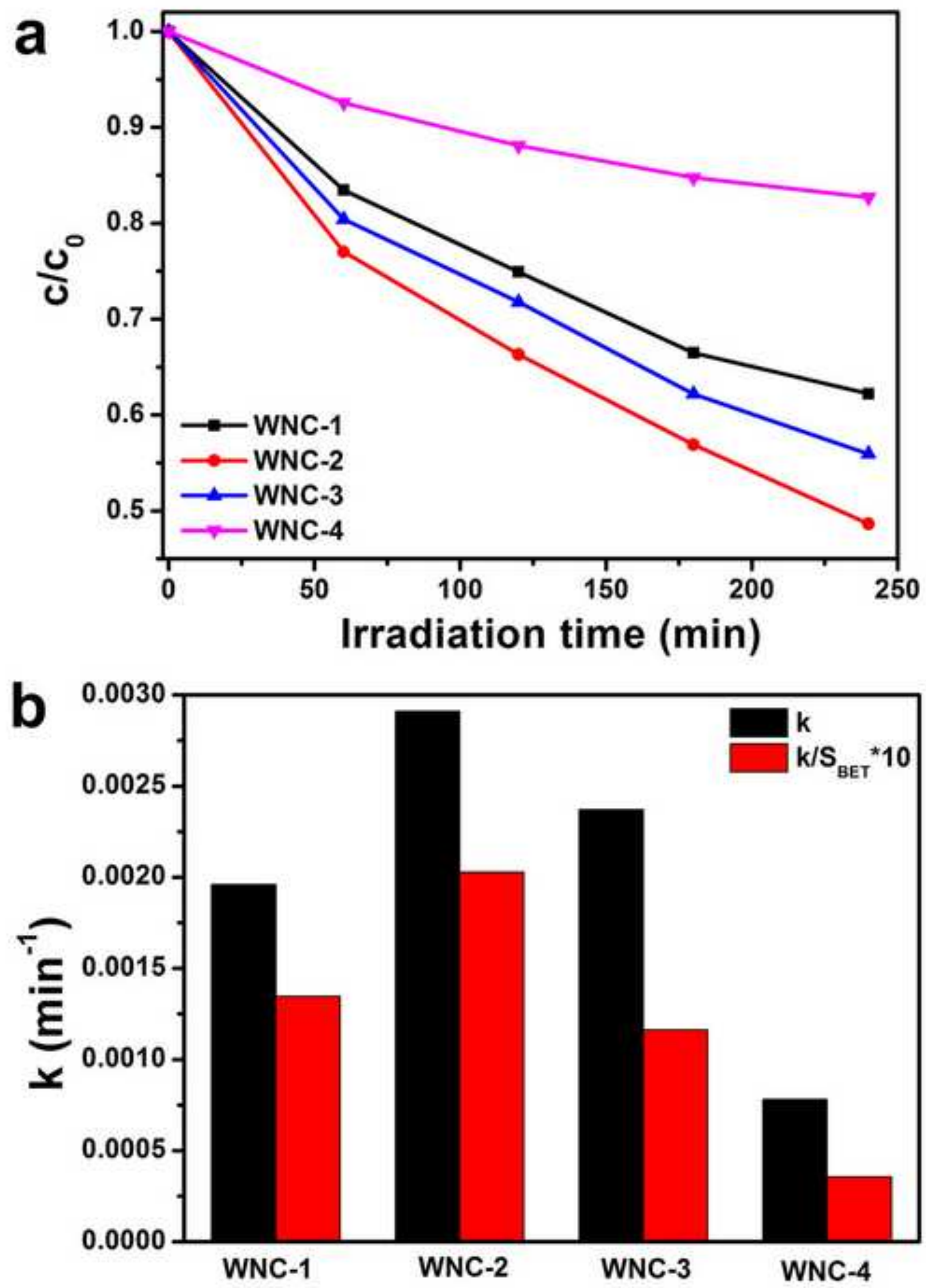

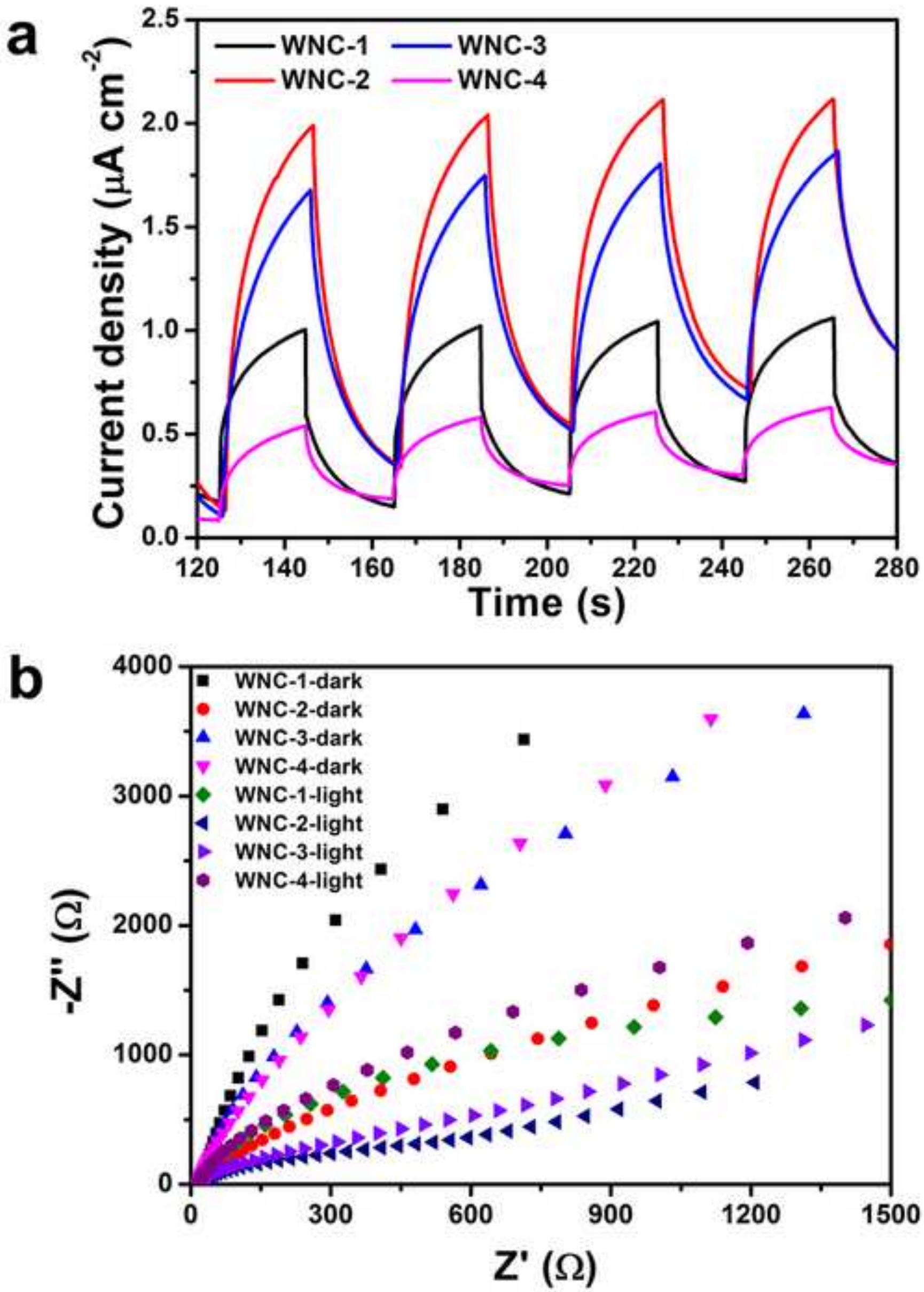
a

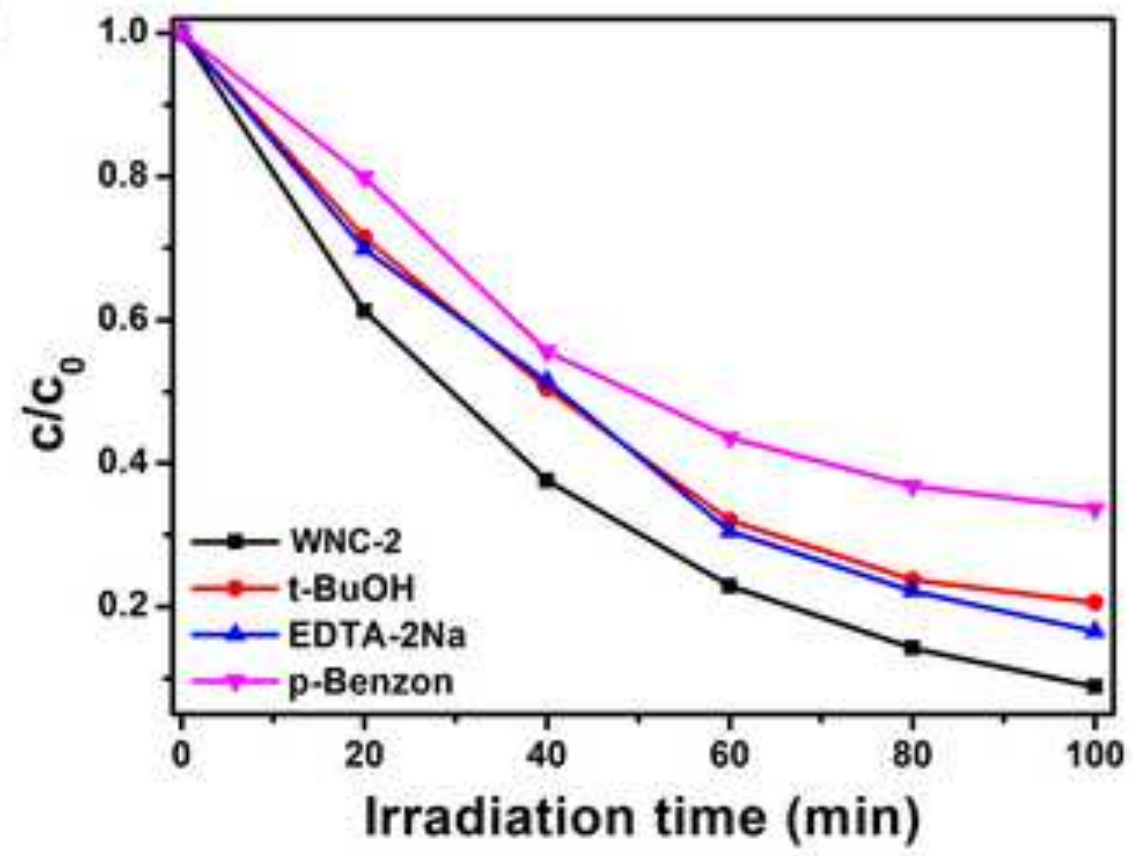

C

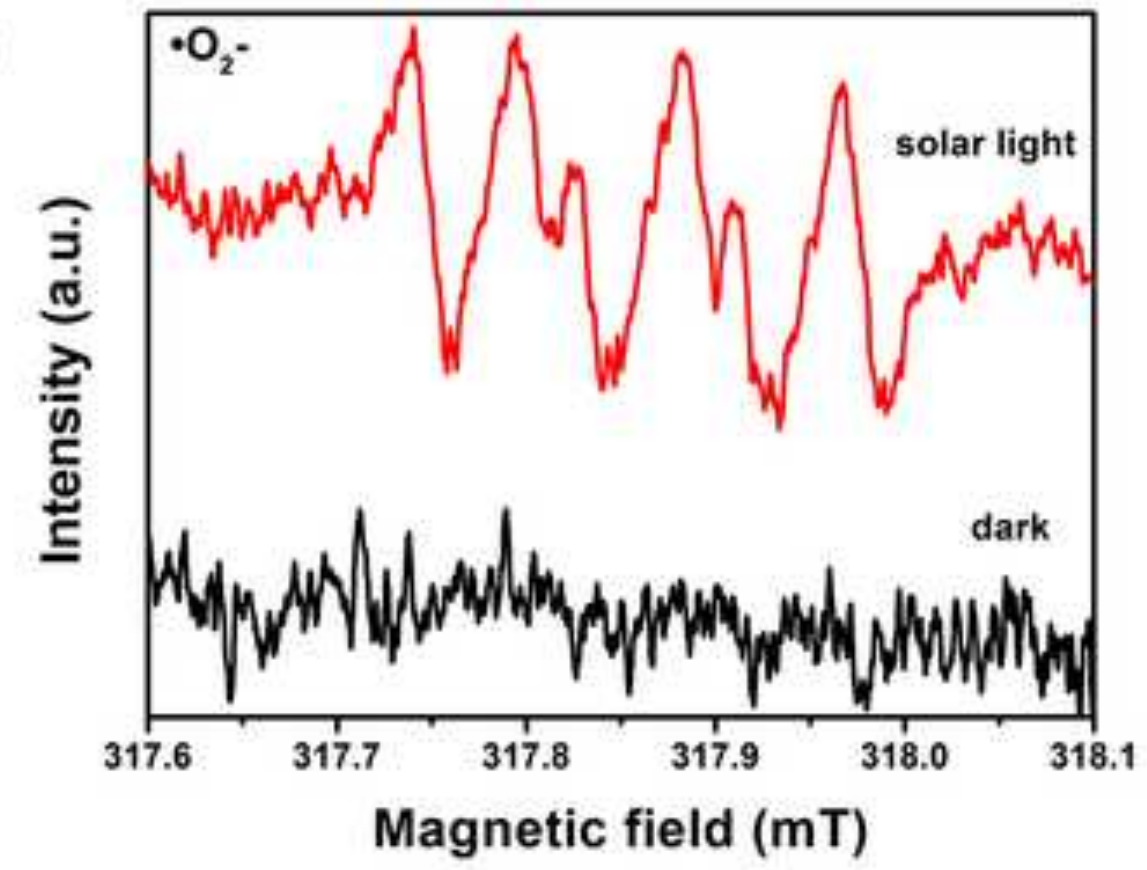

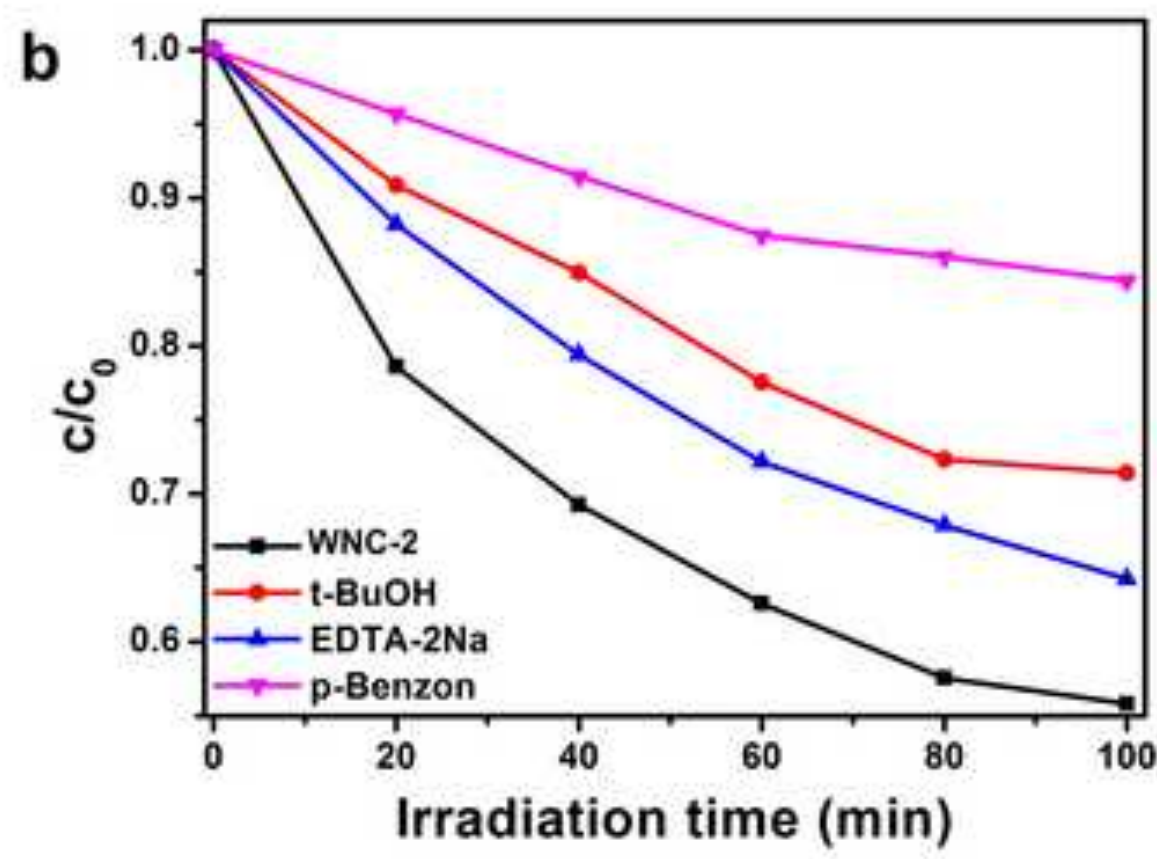

d

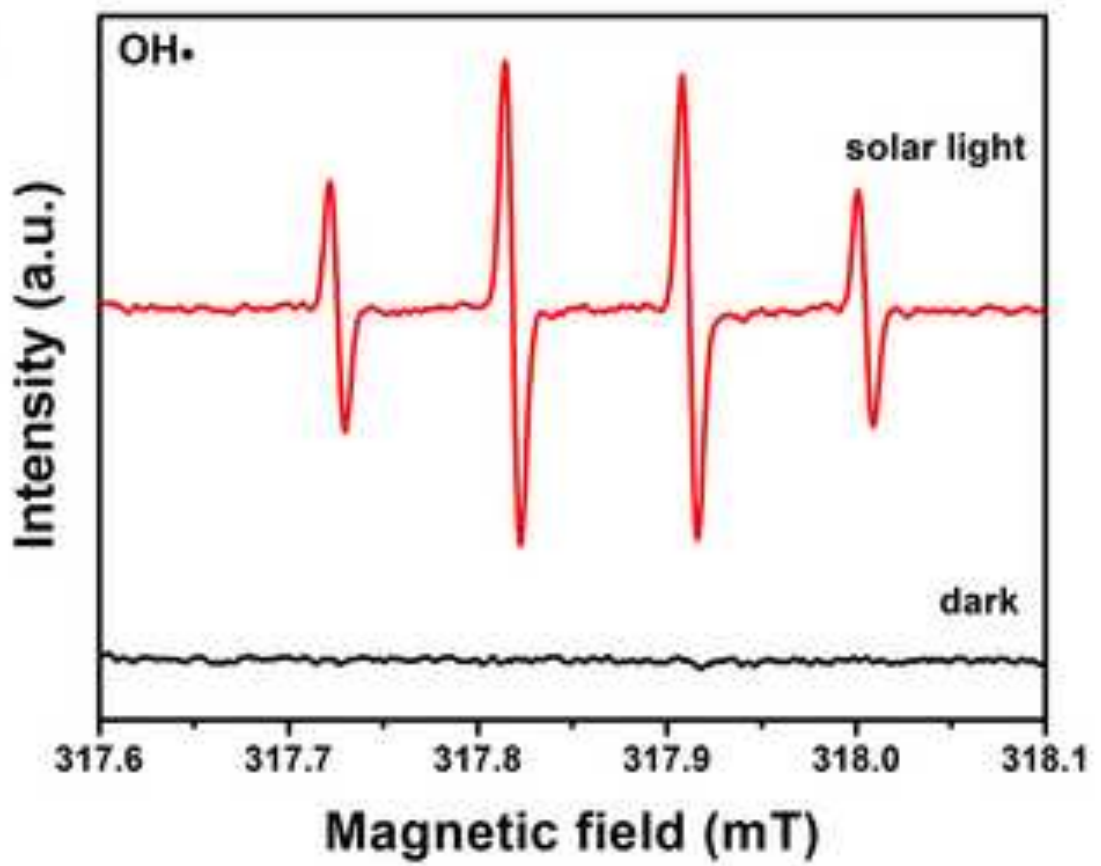




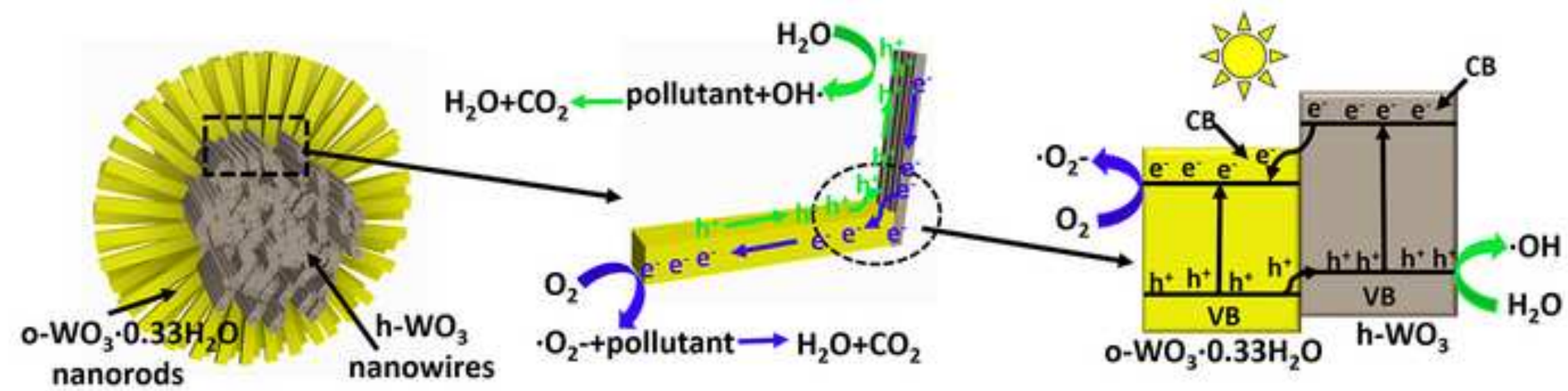

(I)

(II)

(III) 


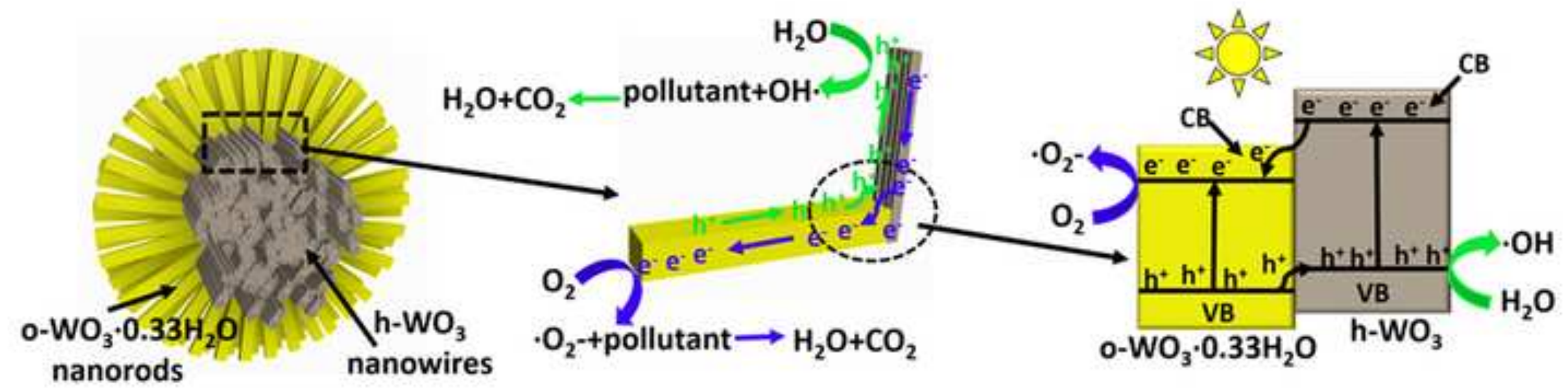

sunflower-like

vertical o- $\mathrm{WO}_{3} \cdot 0.33 \mathrm{H}_{2} \mathrm{O}$ nanorod/ tungsten oxide $\mathrm{h}-\mathrm{WO}_{3}$ nanowire phase junction

band structure 